\title{
Arbuscular Mycorrhizal Fungi Co-Colonizing on A Single Plant Root System Recruit Distinct Microbiomes
}

\section{Jiachao Zhou}

China Agricultural University

\section{Xiaofen Chai}

China Agricultural University

\section{Lin Zhang}

China Agricultural University College of Humanities and Development Studies

\section{Timothy S George}

The James Hutton Institute

\section{Gu Feng ( $\square$ fenggu@cau.edu.cn )}

College of Resource and Environmental Science, China Agricultural University https://orcid.org/00000002-1052-5009

\section{Research}

Keywords: Arbuscular mycorrhizae, 13C-DNA-SIP, Hyphosphere, Microbiome, COG, Hyphal exudates, Mycorrhizal pathway.

Posted Date: September 10th, 2020

DOl: https://doi.org/10.21203/rs.3.rs-73473/v1

License: @ (i) This work is licensed under a Creative Commons Attribution 4.0 International License. Read Full License 
8

9

10

11

12 9 10 1 12

\section{Arbuscular mycorrhizal fungi co-colonizing on a single}

\section{plant root system recruit distinct microbiomes}

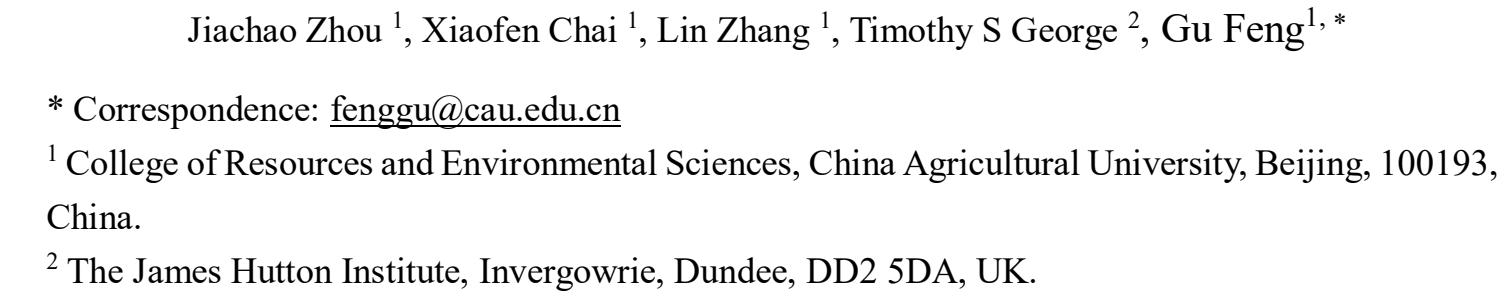

${ }^{*}$ Corresponding author. Tel: +86 10 62733885; fax: +86 1062731016 .

E-mail address: fenggu@cau.edu.cn 


\section{Abstract}

Background: Plant roots are usually colonized by various arbuscular mycorrhizal (AM) fungal species which vary in morphological, physiological and genetic traits and constitute the mycorrhizal nutrient uptake pathway (MP) in addition to roots. Simultaneously, the extraradical hyphae of each AM fungus is associated with a community of bacteria. However, whether the community structure and function of microbiome on the extraradical hyphae would differ between the AM fungal species are mostly unknown.

Methods: In order to understand the community structure and the predicted functions of the microbiome associated with different AM fungal species, a split-root compartmented rhizobox culturing system, which allowed us to inoculate two AM fungal species separately in two root compartments was used. We inoculated two separate AM fungal species combinations, Funneliformis mosseae (F.m) and Gigaspora margarita (G.m), Rhizophagus intraradices (R.i) and G. margarita, on a single root system of cotton. The hyphal exudate fed active microbiome was measured by combining ${ }^{13} \mathrm{C}$-DNA stable isotope probing with Miseq sequencing.

Results: We found different AM fungal species, that were simultaneously colonizing on a single root system, hosted distinct active microbiomes from one another. Moreover, the predicted potential functions of the different microbiomes were distinct.

Conclusion: We conclude that the arbuscular mycorrhizal fungi component of the system is responsible for the recruitment distinct microbiomes in the hyphosphere. The potential significance of the predicted functions of the microbiome ecosystem services is discussed.

Key words: Arbuscular mycorrhizae; ${ }^{13}$ C-DNA-SIP; Hyphosphere; Microbiome; COG; Hyphal exudates; Mycorrhizal pathway. 


\section{Background}

The plant- arbuscular mycorrhizal (AM) fungi symbiosis has existed for over 460 Mya [1]. Consequently, over $80 \%$ of terrestrial plants form a symbiosis with arbuscular mycorrhizal (AM) fungi for efficient nutrient uptake, or to confer resistance to stress [2]. Exploitation of these symbioses is of high environmental and economic value [3]. Like plant roots, AM fungi produce large networks of extraradical hyphae in the soil, release carbon and recruit free-living soil microbes to colonize the hyphae [4-7]. In recent years, an intimate cooperative relationship between AM fungal hyphae and bacteria has been observed, supported by multiple lines of evidence such as microscopic observations [8] and molecular analyses [5]. Bacteria associated with AM fungi (hyphosphere) have been identified as the third component of the plant-AM fungi symbiosis because of the critical role they play in mycorrhizal function $[3,6,9,10]$. Revealing the secrets of hyphosphere microbiomes is essential for better understanding of the belowground ecosystem.

Many factors such as soil $\mathrm{pH}$ and its spatial structure have been identified to influence the bacterial community associated with plant roots, while AM fungi was identified as the major factor which determined it [11]. In natural and agricultural systems, the root system of a mycorrhizal plant is usually simultaneously colonized by diverse AM fungal species [12]. The co-colonizing AM fungi have different morphological, physiological and genetic characteristics [13-18]. The coexisting AM fungal species show different contributions to the growth and $\mathrm{P}$ uptake of the host plant [15]. For example, Glomus intraradices can rapidly colonize available $\mathrm{P}$ patches beyond the root surface and transport significant amounts of $\mathrm{P}$ towards the roots, while G. margarita has been shown to provide P benefits to the plants by forming dense mycelium networks close to the roots where remaining soil $\mathrm{P}$ was less available [15]. 
In addition, recent decoding of the whole-genome sequence of AM fungi suggest that there is large variation in the genetic control of functions [16], e.g. G. rosea contains a much greater secretome size and more secreted proteins (SSP) than Rhizophagus sp. [16]. Collectively, the above morphological, physiological and genetic differences indicate that the hyphal exudates of AM fungal species are likely to be different, which in turn are likely to lead to differences in the hyphosphere microbiome community structure and function. However, at present no direct evidence exists which show the difference between fungal species co-colonizing on a single plant root system. Therefore, to uncover such difference is fundamental for understanding the central question in fungi-bacteria interaction research: how bacteria and mycorrhizal fungi associate and become mutually beneficial neighbors [3].

Several factors may affect the results of hyphosphere microbial community composition in plant-AM fungi-soil system. First, plant root exudates are an important factor in the recruitment of soil microbial community. In order to get direct evidence of the effect of hyphae exudates on hyphosphere microbiome characteristics, it is essential to separate their influence away from that of the root exudates. Second, the vitality of AM fungal hyphae is important. Previous studies have shown that soil bacteria differ in their ability to colonize vital and nonvital hyphae and that this can also be influenced by the arbuscular mycorrhizal fungal species involved [19]. Therefore, a method that can test the vital and nonvital hyphae is necessary to identify the hyphosphere microbiome. Third, the feedback effects of plant on the growth of AM fungus due to changes in plant physiology induced by the fungus $[20,21]$ is critical. In the past, splitroot methods were used to quantify $\mathrm{C}$ allocation to different AM fungal species cocolonizing on a single root system of plant [22] in order to assess this factor.

In this study, we hypothesized that the different AM fungal species that colonized 
on a single root system would recruit distinct microbiomes. To test our hypothesis, we developed a new integrated approach to avoid the above influences. We grew cotton (Gossypium hirsutum L.) plants in a split-root and compartmented rhizobox in which a buffer zone was set to prevent root exudate diffusing into the hyphal compartment and to avoid feedback effects. We inoculated two different AM fungal species combinations Funneliformis mossea/Gigaspora margarita (F.m/G.m) or Rhizophagus intraradices/Gigaspora margarita (R.i/G.m) to both root compartments. We used ${ }^{13} \mathrm{CO}_{2}$ to pulse label the plant-AM fungi-hyphae associated bacteria during the last week before harvest and tested active hyphal associated microbiomes by ${ }^{13} \mathrm{C}$-DNA-SIP (stable isotopic probing) method and Miseq high-throughput sequencing.

\section{Results}

\section{Mycorrhizal colonization}

We used the DNA copy number in roots to indicate the colonization of each AM fungal species. Based on the principles of qPCR, any measurement that is less than 100 copies can be considered background and indicative of a lack of presence of mycorrhizal DNA [18]. In NM controls in both Exp 1 and Exp 2, the root AM fungal DNA copy number was below this threshold, indicating that no AM fungus was detected in the roots. Both species of AM fungi were able to colonize the root system of the same plant effectively at the same time. In Exp 1, after inoculation with $F$. mosseae, the root AM fungal DNA copy number significantly increased to $10^{7}$; and inoculation with G. margarita increased the AM fungal DNA copy number to $10^{5}$, which was significantly less than that of the concomitant inoculation with F. mosseae $(P<0.01)$ (Fig. 2a). In Exp 2, after inoculation with $R$. intraradices, the root AM fungal DNA copy number significantly increased to $10^{7}$; and inoculation with G. margarita increased the AM fungal DNA copy number to $10^{5}$, significantly less than that of 
concomitant inoculation with $R$. intraradices $(P<0.01)$ (Fig. 2a).

\section{Hyphal length density in HCs soil}

In the NM control in both Exp 1 and Exp 2, less than $0.6 \mathrm{~m} \mathrm{~g}^{-1}$ soil of hyphae was detected, implying there were some saprotrophic fungi in compartments. In Exp 1, the hyphal length density of $F$. mosseae was more than $6 \mathrm{~m} \mathrm{~g}^{-1}$ soil, while the density of $G$. margarita was about $3 \mathrm{~m} \mathrm{~g}^{-1}$ soil. G. margarita produced significantly $(P<0.001)$ less hyphal length than F. mosseae (Fig. 2b). Similarly, in Exp 2, the hyphal length density of $R$. intraradices was $6 \mathrm{~m} \mathrm{~g}^{-1}$ soil while that of $G$. margarita was only $3 \mathrm{~m} \mathrm{~g}^{-1}$ soil, significantly $(P<0.001)$ less than that of $R$. intraradices (Fig. 2b).

\section{Biomass, $P$ concentration and $P$ content of shoot}

The cotton plants grew well after being transplanted into the split-root microcosm (See Fig. S2). At harvest, the shoot biomass and $\mathrm{P}$ concentration and $\mathrm{P}$ content data of all inoculation treatments were significantly $(P<0.01)$ greater than those of their NM control treatments, respectively (Table 1).

\section{${ }^{13} \mathrm{C}$ incorporation of $\mathrm{HCs}$ soil and bacteria}

The DNA of targeted bacterial populations in the hyphosphere was successfully labeled by ${ }^{13} \mathrm{C}$. In the NM control, the isotopic signature $\left(\delta^{13} \mathrm{C}\right)$ of hyphosphere soil was consistent with the atmospheric concentration (approximate -20\%). The isotopic signatures in the HCs of inoculated treatments were greater than that of NM control (Fig. 2c). In addition, inoculation with $F$. mosseae and $R$. intraradices resulted in much greater ${ }^{13} \mathrm{C}$ abundance than that of G. margarita in Exp 1 and Exp 2, respectively (Fig. 2c). The incorporation of ${ }^{13} \mathrm{C}$ into bacterial DNA in the hyphosphere soil was corroborated by parallel incubation of microcosms labeled with ${ }^{12} \mathrm{C}$. The gradients in all ${ }^{12} \mathrm{C}$ labeled soil after seven days clearly showed peaks of bacterial DNA in a 'light' DNA fraction. In contrast, the bacterial DNA in all ${ }^{13} \mathrm{C}$ labeled soil had apparently 
shifted toward 'heavier' buoyant densities (Fig. S3).

\section{Taxonomic profiling of bacteria associated with AM fungal hyphae}

The DNA from the selected fractions shown in Figure S2 was sequenced using a high-throughput MiSeq PE 300 platform. After quality filtering and standardizing of the raw data, a dataset of 1989255 high-quality sequences with an average length of $439 \mathrm{bp}$ and over 24433 reads per sample was generated. At $97 \%$ similarity, the number of operational taxonomic units (OTUs) ranged from 505 to 836, depending on the sample (Fig S4). The microbiome of ${ }^{13} \mathrm{C}$-labeled samples was considered as the active one, which were influenced by the hyphae directly [23]. So, the following analyses were all based on the ${ }^{13} \mathrm{C}$-labeled active samples.

\section{The effect of AM fungi hyphae on soil microbiome}

After aligning the OTUs with the Greengenes database, the soil microbial community was classified into phylotypes consisting of 10 dominant phyla and others. The dominant taxa included Proteobacteria, Actinobacteria, Firmicutes and Gemmatimonadetes, Bacteroidetes, Chloroflexi, Acidobacteria, Cyanobacteria, Planctomycetes and Fusobacteria, which contributed to over 95\% of the whole community in all conditions (Fig. S5). There was a significant difference in the abundance of some taxa compared with NM control after inoculation. However, the difference in taxa abundance was dependent on the AM fungal species (Fig. S5). For example, compared to the NM control, (i) the hyphosphere of $F$. mosseae contained a greater abundance of Actinobacteria and Gemmatimonadetes, but contained fewer Proteobacteria, Bacteroidetes, Acidobacteria and Planctomycetes. (ii) the hyphosphere of $R$. intraradices contained a greater abundance of Actinobacteria and Firmicutes, but contained fewer Proteobacteria and Bacteroidetes. (iii) the hyphosphere of G. margarita contained a greater abundance of Proteobacteria, Cyanobacteria and Fusobacteria, but 
fewer Gemmatimonadetes, Chloroflexi, Acidobacteria and Planctomycetes (Fig. S5). In addition, the PCA analysis also showed the community structure of the inoculated hyphal compartments was different to the NM control (Fig. S6).

The difference between microbiome diversity associated with the hyphae of different AM fungi

In Exp 1, there was no difference was observed in OTUs number of F. mosseae hyphosphere microbiome than that of G. margarita, while in Exp 2, 100 more OTUs were observed in $R$. intraradices hyphosphere microbiome than that of G. margarita (Fig. S4). In addition, there was a significant difference in the abundance of different taxa between different AM fungal species (Fig. 3 and 4). At the phylum level, the abundance of Proteobacteria, Cyanobacteria and Fusobacteria in the hyphosphere of $G$. margarita was much greater than that of $F$. mosseae and $R$. intraradices, both in Exp 1 and Exp 2. However, G. margarita exhibited a smaller abundance of Actinobacteria, Gemmatimonadetes and Planctomycetes (Fig. 3). There was no significant difference in the abundance of Firmicutes, Chloroflexi, Bacteroidetes, and Acidobacteria, between F. mosseae and G. margarita or between R. intraradices and G. margarita in Exp 1 and Exp 2, respectively (Fig. 3).

At the genus level, there were a total of 733 genera observed in this study. We only considered the genus whose abundance was over $1 \%$ as the dominant taxa. In Exp1, 16 genera were identified as dominant taxa both in F. mosseae and G. margarita hyphosphere microbiome. However, only 7 of them were both dominant in two different AM fungal hyphosphere. In Exp2, 18 genera and 15 genera were identified as dominant in R. intraradices and G. margarita hyphosphere, respectively. Only 5 genera were both dominant in these two different AM fungal hyphosphere in Exp 2. Of all the genera, 92 genera which contained most of the dominant genera were observed as being 
different between the microbiomes associated with F. mosseae and G. margarita extraradical hyphae in Exp 1, this represented approximately $70 \%$ of total abundance. Likewise, there were 108 genera which contained most of the dominant genera were observed as being different between G. margarita and R. intraradices in Exp 2, representing over $80 \%$ of total abundance in the $R$. intraradices hyphosphere and over $50 \%$ in the G. margarita hyphosphere, respectively (Fig. 4). In accordance with this, the PCA analysis results demonstrated that there was a significant difference between F. mosseae and G. margarita or R. intraradices and G. margarita community structure in Exp 1 and Exp 2, respectively (Fig. 6).

\section{The Cluster of Ortholog Genes (COG) functional pathway prediction}

Twenty-two COG pathways were predicted through $16 \mathrm{~S}$ rDNA sequencing of ${ }^{13} \mathrm{C}$ labeled samples. These included all bacterial growth processes such as reproduction, organic or inorganic nutrient metabolism, signaling and immunity (Fig. 7). Eleven COG functional pathways, which contained over half of all the pathways obtained significantly different abundance between F. mosseae and G. margarita in Exp1 (Fig. 7). In detail, the relative abundance of Amino acid transport and metabolism, Cell motility, Coenzyme transport and metabolism, General function prediction only, Intracellular trafficking, secretion, and vesicular transport and Transcription were greater in the G. margarita hyphosphere microbiome. While the relative abundance of Carbohydrate transport and metabolism, Defense mechanisms, Energy production and conversion, Secondary metabolites biosynthesis, transport and catabolism and Translation, ribosomal structure and biogenesis were much more prevalent in $F$. mosseae hyphosphere microbiome. Fifteen COG pathways showed a significant difference between $R$. intraradices and G. margarita, while eight of them were greater in the $R$. intraradices hyphosphere (Fig. 7). In detail, Cell cycle control, cell division, 
chromosome partitioning, Cell motility, Coenzyme transport and metabolism, Inorganic ion transport and metabolism, Intracellular trafficking, secretion, and vesicular transport, Posttranslational modification, protein turnover, chaperones, Replication, recombination and repair and Signal transduction mechanisms were much more prevalent in G. margarita hyphosphere microbiome. While the relative abundance of Carbohydrate transport and metabolism, Cytoskeleton, Defense mechanisms, Lipid transport and metabolism, RNA processing and modification, Secondary metabolites biosynthesis, transport and catabolism and Transcription were much greater in $R$. intraradices hyphosphere microbiome. Most interestingly, carbohydrate transport and metabolism pathways represented over $6 \%$ of all the results, and G. margarita exhibited a smaller abundance of these pathways than $F$. mosseae and $R$. intraradices in Exp 1 and Exp 2, respectively (Fig. 7).

\section{Discussion}

Validation of a novel method for separating out the impact of AM fungi on the soil microbiome

Traditionally, mycorrhizal colonization is measured by staining and microscopic observation methods [24]. In contrast, in this study we used q-PCR to quantify the DNA copy number to indicate mycorrhizal fungi colonizing statue with species specific $18 \mathrm{~S}$ rRNA primers. There is a background threshold of 100 copies in the AM fungi DNA qPCR process that dictates the presence or absence of AM fungi [18]. Our results suggested that all inoculated treatments have many orders of magnitude more DNA copies than those of control treatments (Fig. 2a). In addition, no other non-targeted AM fungus was found in any sample through PCR using AM fungal specie specific primers. Such results suggest that all inoculated AM fungi were well colonized in the split-root system of cotton without contamination. 
In this study, we compared the bacterial community that associated with the hyphae (representing the hyphosphere microbiome) with the bacterial community in the soil collected from HCs of non-mycorrhizal treatments (representing the bulk soil). As the diameter of AM fungal hyphae is so small that is difficult to separate soil particles from the hyphae, we therefore used the bacteria that were tightly colonizing on the hyphal surface to indicate the status of the hyphosphere bacterial community.

To avoid any influence of root exudates on the measurements, we set a $1 \mathrm{~cm}$ wide buffer zone in which we added sterilized mixture of glass beads and fine clay soil which was sieved through $30 \mu \mathrm{m}$ nylon mesh. Our results showed that $\delta^{13} \mathrm{C}$ of the HCs soils of the control treatments were the same as the background, suggesting no direct influence from root exudate on the microbiome community in HCs. Therefore, all differences between hyphosphere and bulk soil or between the different AM fungal species can be attributed to the effects of hyphal exudation.

As the turnover rate of AM extraradical hyphae is fast [25], both vital and nonvital hyphae exist simultaneously, importantly it is thought that the bacterial communities associated with these two types of hyphae may differ [19]. To avoid these influences, we took a seven-day-pulse labelling approach in the last week before harvesting, which ensures that, all the ${ }^{13} \mathrm{C}$ labelled extraradical mycelium were vital, because the potential turnover time of AM fungal hyphae is 5-6 days [25]. We assume nonvital hyphae will not consume the ${ }^{13} \mathrm{C}$ labelled carbohydrates because the senescent hyphae form sepat to cease the protoplasm flow in hyphae. Therefore, the atom percent of ${ }^{13} \mathrm{C}$ of the samples in HCs indicated the allocation of photosynthetic products to vital extraradical hyphae and hyphae associated with soil particle and bacteria, and the ${ }^{13} \mathrm{C}-\mathrm{DNA}-\mathrm{SIP}$ identified hyphosphere microbiome were active hyphae exudates consumers.

\section{The influence of AM extraradical hyphae exudates on biophysical distribution}




\section{of soil microbial community and biodiversity}

Arbuscular mycorrhizal fungi produce a large network of extraradical hyphae in soil and provide a carbon rich habitat for soil microbes [5,6], which induces colonization of diverse groups of bacteria forming the hyphosphere [7,26,27]. Our current study not only further supports those previous findings but provided novel findings as well. First, the differences in q-PCR (Fig. 2a) and plant biomass (Table 1) results between F.mosseae/G.margarita and NM in Exp 1 or R.intraradices/G.margarita and NM in Exp 2 indicated that all AM fungal species colonized roots of cotton and played a role in promoting plant growth. Second, we successfully separated the active bacteria that consumed hyphal exudates by ${ }^{13} \mathrm{C}-\mathrm{DNA}-$ SIP plus Miseq sequencing methods (Fig. S3). Compared to bulk soil, we found that only part of the soil microbiome was ${ }^{13} \mathrm{C}$-labelled on the hyphae of the AM fungi which we defined as the active hyphosphere microbiome (Fig. S4). Third, the co-colonizing AM fungi all formed a unique bacterial community around the extraradical mycelium (Fig S3 and Fig. S5). Our observations help us understand biophysical mechanisms which dictate the heterogeneous distribution of the microbiome at the micro-scale [2830]. Our current finding provides new and direct evidence that shows that AM fungal hyphae, most likely through their exudates, are one of the major driving forces for formation of the bacteria mosaic at micrometer scale in soil. As AM fungi use up to $20 \%$ of plant photosynthesis products and form several meters to tens of meters of hyphae in one gram of soil [31], understanding of such mechanisms have significance even within the context of the global soil microbial biodiversity pattern.

\section{Co-colonizing AM fungal species recruited different active hyphosphere microbiome community}

Although previous studies have shown that a range of AM fungal species, which 
are different in morphological structure, hyphal distribution pattern and their metabolic traits, can simultaneously colonize a single root system $[15,32,33]$. Whether or not these fungi recruit different microbiome with their own preference is still an open question. between the two HCs in Exp 1 and Exp 2 can be attributed to the differences in traits of excretion of exudates between the two AM fungal species. Our ${ }^{13} \mathrm{C}-\mathrm{DNA}-\mathrm{SIP}$ plus pyrosequencing results supported the hypothesis. First, different AM fungal species produced differing amounts of hyphae in HCs (Fig. 2b). Compared to G. margarita, the HCs of both $F$. mosseae and $R$. intraradices contained a greater ${ }^{13} \mathrm{C}$ abundance. Second, there were more OTUs in the microbiome of $F$. mosseae and $R$. intraradices hyphosphere than that of G. margarita in Exp 1 and Exp 2, respectively (Fig. S4). More importantly, the abundance and structure of over half of the bacteria, at both phyla and genera levels, showed a significant difference between F. mosseae and G. margarita in

Exp 1 and between R. intraradices and G. margarita in Exp 2 (Fig. 3, 4, 5 and 6). All species were distinct.

Previous studies have indicated that the hyphosphere microbiome are directly involved in soil organic N, P, C mineralization [7,27,31,34,35]. For example, Pseudomonas and Bacillus are reported to have abilities to mobilize sparingly soluble $\mathrm{P}$ in soil (Table S5)[5,7]. In the current study, G. margarita harbored greater abundance of Pseudomonas, but fewer Bacillus than those of F. mosseae or R.intraradices. In addition, some soil bacteria, called mycorrhiza helper bacteria (MHB), can help AMF colonize more into the root or branch more [9]. MHB belong to many taxa such as Proteobacteria (Agrobacterium, Azospirillum, Azotobacter, Burkholderia, 

Streptomyces, and Arthrobacter) and even some unculturable bacterial taxa such as Acidobacteria (Acidobacterium) [36] (Table S6). However, MHB are often AM fungal specificity, which means they can stimulate mycorrhiza formation and extraradical hyphae production for some AMF but inhibit these mycorrhizal traits for the others [37]. For example, Streptomyces sp. enhanced the colonization of $R$. intraradices (formerly named Glomus intraradices) but inhibited the growth of Hebeloma cylindrosporum $[38,39]$. Here, we found that the abundance of Streptomyces and Bacillus were much greater in the hyphosphere of $R$. intraradices and $F$. mosseae than that of $G$. margarita, while G. margarita which contained the largest abundance of Pseudomonas. These observations suggest that different AM fungal species might cooperate with different functional bacteria and have different impacts on the function of the hyphosphere. The COG functional prediction also supported this assertion, indicating that distinct microbiomes recruited by different AM fungi contained different abundance of inorganic P mobilization abilities or other functions (Fig. 7). Further studies are needed to investigate the functions of the hyphosphere microbiome in specific nutrition cycling. particle continuum system and therefore to growing our food sustainably and with minimal environmental impact, protecting against pathogens and disease, while also providing important ecological services such as nutrient turnover and transformation and bioavailability. Understanding the structure of the microbiome is essential for using the native microbiome efficiently [40]. In recent years, mycorrhizal genome sequencing studies have found that mycorrhizal fungi have lost many saprophytic genes in the longterm co-evolution process with plants [16]. Cooperating with functional microbiomes, 
such as phosphatase releasing bacteria $[6,41]$ is considered an important strategy for AM fungi to compensate their lack of ability to utilize organic P. We find for the first time that different living AM fungi species that colonized single plant root recruit active microbiomes which are distinct from each other. The research not only provides direct evidence for understanding the biophysical process that AM fungal hyphae exudates drive the formation of soil bacteria diversity heterogeneity, but also reveals the potential division of labor may exist in plant-AM fungi-bacteria system that still remains to be understood fully. Greater knowledge of these key interactions in the hyphosphere has from Tai'an, Shandong province, China $\left(36^{\circ} 10^{\prime} \mathrm{N}, 117^{\circ} 09^{\prime} \mathrm{E}\right)$ was used. potential to allow us to more effectively manage the utilization of resources in agricultural systems and help us improve future agricultural sustainability.

\section{Materials and Methods}

\section{Soil}

Physicochemical properties of the soil are presented in Table S1. The collected soil was air dried and sieved ( $2 \mathrm{~mm})$. The basal nutrients were added to the soil as described in Table S2. The soil was sterilized by gamma irradiation ( $25 \mathrm{kGy}, 60$ Co $\gamma$-rays) in the Beijing Atomic Energy Research Institute to eliminate indigenous microorganisms and mycorrhizal propagules before use. Previous studies have demonstrated that AM fungi recruited a hyphosphere microbiome that has the potential to stimulate the solubility of organic $\mathrm{P}[6,7]$. In this study, to enhance the colonization of soil microbiome in hyphosphere, $100 \mathrm{mg} \mathrm{kg}^{-1}$ myo-inositol hexaphosphate calcium magnesium salt (phytin, TCI, Tokyo, Japan) (equaling to $20 \mathrm{mg} \mathrm{P} \mathrm{kg}^{-1}$ soil) was added to the hyphal compartment as an organic $\mathrm{P}$ resource. In order to induce the AM fungal hyphae to release protons to acidify the hyphosphere soil, $\left(\mathrm{NH}_{4}\right)_{2} \mathrm{SO}_{4}$ was provided as the $\mathrm{N}$ 
source [42]. In addition, a nitrification inhibitor 3,4-dimethylpyrazole phosphate (DMPP; 'ENTEC Flüssig' produced by EuroChem Agro GmbH, Mannheim, Germany) was also added, at a rate of $1 \%(\mathrm{w} / \mathrm{w})$ of the $\mathrm{N}$ applied to prevent nitrification of $\left(\mathrm{NH}_{4}\right)_{2} \mathrm{SO}_{4}$.

\section{Microcosms}

In order to test whether the extraradical mycelium of each AM fungal species that simultaneously colonized on the same root system would recruit their own microbiome, we used a split-root and compartmented microcosms system that was able to separate the growing spaces of root systems and the extraradical mycelium of two AM fungal species (Fig. 1). The microcosms were constructed using PVC plates, and consisted of four compartments. The two middle compartments were separated by PVC plates and were used for split-root growth (root compartment, RCs). The two outer compartments (hyphal compartment, HCs) were separated from the RCs by a $1 \mathrm{~cm}$ buffer zone. The buffer zone consisted of two-layers of $30 \mu \mathrm{m}$ nylon mesh, which allowed AM fungal hyphae to pass through, but prevented root penetration. In order to easily extract the hyphae, the fine soil used in HCs was sieved with a $30 \mu \mathrm{m}$ mesh. In short, fine soil was prepared by wet sieving. Approximately $1 \mathrm{~kg}$ of air-dried soil was placed into a $5 \mathrm{~L}$ bucket, 3-4 L tap water was added, and the soil was brought into suspension by stirring. The soil suspension was poured through a sieve with a mesh width of $30 \mu \mathrm{m}$. This procedure was repeated three times on each $1 \mathrm{~kg}$ soil portion. The sieved soil suspension was collected in another bucket and allowed to settle until the water above the soil layer became clear and was siphoned off using a flexible tube. The remaining sludge was transferred to a shallow, heat-resistant dish and was dried at $60^{\circ} \mathrm{C}$ until the material became solid. The fine soil was then mixed with glass beads ( $1 \mathrm{~mm}$ in diameter) by 1:1 $(\mathrm{w} / \mathrm{w})$ ratio. The mixture was sterilized by gamma irradiation ( $25 \mathrm{kGy}, 60 \mathrm{Co} \gamma$-rays) in 
the Beijing Atomic Energy Research Institute. The microcosms received the following amounts of soil or soil-glass bead mixture: $500 \mathrm{~g}$ soil in each RC and $165 \mathrm{~g}$ soil-glass bead mixture in each buffer zone and $495 \mathrm{~g}$ soil-glass bead mixture in each HC. The soil or soil-glass bead mixture was filled very carefully to each compartment to maintain equal bulk density in each $\mathrm{HC}$.

\section{Host plants}

Cotton (Gossypium herbaceum L., cv. Xinluzao 32) seeds were surface-sterilized with $10 \%(\mathrm{v} / \mathrm{v}) \mathrm{H}_{2} \mathrm{O}_{2}$ [42], and germinated on moist filter paper for 2 days at $26^{\circ} \mathrm{C}$ in the dark. The seeds were then transferred to $40 \times 25 \mathrm{~cm}$ moist filter paper for 17 days (12 $\mathrm{h}$ light, $12 \mathrm{~h}$ dark, $26^{\circ} \mathrm{C}$ ) to allow the roots to grow longer. Seedlings of similar size and with nine roots (including taproot) were selected, and one plant was transplanted into each microcosm.

\section{AM fungal and bacterial inoculant}

The inoculum of Rhizophagus intraradices (R.i) (EY108), Funneliformis mosseae (F.m) (MD118) and Gigaspora margarita (G.m) (JA101A) were purchased from the International Culture Collection of(Vesicular) Arbuscular Mycorrhizal Fungi (INVAM). They were propagated through hosts (maize: Nongda 108 and Plantago depressa Wild.) in zeolite and sand for five months; the spore density was about 20 spores $\mathrm{g}^{-1}$ substrate. In order to keep the same RC original microflora, $5 \mathrm{ml}$ of AM fungal inoculum filtrate was added to each RC as described in Table S3. Five ml of soil filtrate was added to the hyphal compartment as the original hyphal compartment microflora. The filtrate of inoculum or soil was obtained by suspending $30 \mathrm{~g}$ of unsterilized inoculum or soil in $300 \mathrm{ml}$ of sterile water and filtration through six-layer quantitative filter paper (properties similar to Whatman Grade 43) [5], which allowed passing of common soil microbes, but effectively retained spores and hyphae of mycorrhizal fungi. 


\section{Experimental design and procedure}

Two single factor experiments were conducted, Experiment 1 (Exp 1) and Experiment $2(\operatorname{Exp} 2)$ which are described in Fig. 1. There were 6 repeats for each treatment, 3 were labeled with ${ }^{13} \mathrm{CO}_{2}$ while the other 3 were given ${ }^{12} \mathrm{CO}_{2}$ treatment as a control. At planting, half of the soil for each RC (250 g) was carefully added to the $\mathrm{RC}$, and then $30 \mathrm{~g}$ AM fungal inoculum of each AM fungal species containing about 600 spores was added to each RC. The taproot of the pre-cultured plant was cut-off at the elongation zone, and the shoot was mounted on the central PVC plate. The two groups of lateral roots were evenly separated into the two RCs. Finally, the remaining $250 \mathrm{~g}$ soil was added to the RCs. The control treatments (NM) in both experiments received the same amount of sterilized inoculum. The HCs and buffer zone were filled with a soil-glass bead mixture, and thus, the substrates in the four sections are referred to as root soil, buffer soil and hyphal soil (Fig. 1). Plants in these microcosms were grown in a campus greenhouse at China Agricultural University in Beijing from 13 May to 8 July 2015 at $24 / 30^{\circ} \mathrm{C}$ (night/day) and an average photosynthetically actively radiation of $360 \mu \mathrm{mol} \mathrm{m} \mathrm{m}^{-2} \mathrm{~s}^{-1}$. To avoid any possible influence of environmental factors in the glasshouse, the position of the microcosms was re-randomized once a week. Soil gravimetrical moisture was kept at 18-20\% (w/w, 70\% water holding capacity) with deionized water added to weight every 2 days during the experiment.

\section{${ }^{13} \mathrm{CO}_{2}$ pulse labeling chamber and procedure}

To trace the transfer of plant-derived $\mathrm{C}$ from mycorrhizal hyphae to the hyphosphere microbes, ${ }^{13} \mathrm{CO}_{2}$ stable isotope pulse labeling was conducted in the glasshouse for seven days before harvest. Seven weeks after sowing, the cotton plants were subjected to ${ }^{13} \mathrm{CO}_{2}\left(99 \%\right.$ of ${ }^{13} \mathrm{C}$ atom) pulse labeling in an airtight Plexiglas growth chamber (Fig. S1). The plant shoots protruded through the holes and the joins 
between stems and chamber were sealed with silica gel to prevent direct exposure of the soil surface to the ${ }^{13} \mathrm{CO}_{2}$ labeling. During pulse labeling, a cooling system was used to cool the chamber temperature to $35^{\circ} \mathrm{C}$. A $100 \mathrm{ml}$ aliquot of ${ }^{13} \mathrm{CO}_{2}$ was injected through the septum using a gas-tight syringe every hour from 9 am to $5 \mathrm{pm}$, the period in which photosynthesis was the greatest during the day [43]. During this process, $\mathrm{CO}_{2}$ concentration was measured using an infrared gas analyzer. The $\mathrm{CO}_{2}$ concentration reached about $450 \mu \mathrm{M}$ after injecting, and about $10 \mu \mathrm{M}$ before injecting. The lid was removed one hour after the last $\mathrm{CO}_{2}$ injection, when the ${ }^{13} \mathrm{CO}_{2}$ concentration in the chamber had decreased to atmospheric levels. The plants were labeled for seven days. Simultaneously, the same procedures of ${ }^{12} \mathrm{CO}_{2}\left(99 \%\right.$ of ${ }^{12} \mathrm{C}$ atom) labeling control were also performed [5]. To remove the influence of vapor produced by plant evaporation during $\mathrm{CO}_{2}$ labeling on photosynthesis, three trays of $\mathrm{CaCl}_{2}$ (100 g per tray) were placed in the chamber. The wet $\mathrm{CaCl}_{2}$ trays were removed and dried in a forced-air oven at $105^{\circ} \mathrm{C}$ for $2 \mathrm{~h}$ every day after the lid of the chamber was removed in the evening and re-used repeatedly.

\section{Harvest and sample analysis}

The plants were harvested eight weeks after planting. To prevent contamination of the hyphal samples with exotic bacteria settling on the surface soil, we removed the top $1 \mathrm{~cm}$ of soil to reduce any potential contamination. The soil in the buffer zone was removed before collecting the soil from the hyphal compartment. Soil from two HCs of NM treatments was mixed as one sample. A part of the soil was stored at $4^{\circ} \mathrm{C}$ for soil tests and another part was immediately frozen in liquid nitrogen and stored at $-80^{\circ} \mathrm{C}$ until DNA extraction for microbial diversity tests could be performed. The shoots were oven-dried before measuring the dry weight and processing for shoot $\mathrm{P}$ concentration.

$$
\text { Determination of shoot } \mathrm{P} \text { concentration was performed according to the method of }
$$


Thomas et al. (1967) [44].

Root DNA was extracted using a Tiangen plant genome Kit (Tiangen Co Lt., Beijing, China) following the manufacturer's instructions, the AM fungal gene copies were detected to assess AM fungal root colonization rate. The AMF copies were quantified in triplicate by real-time q-PCR in a q-TOWER q-PCR analyzer (Jena, Germany) using root DNA extracted from each treatment with AM fungi specific primers (Table S4) and using the methods described in supplementary materials. The hyphal length density of $\mathrm{HC}$ soil was determined according to the method of Jakobsen et al. (1992) [45].

\section{${ }^{13} \mathrm{C}$ DNA stable isotope probing (SIP) analysis}

Soil samples stored at $4^{\circ} \mathrm{C}$ were oven-dried at $70^{\circ} \mathrm{C}$, ground, sieved using an 80 $\mu \mathrm{m}$ mesh and then the $\delta^{13} \mathrm{C} \%$ was determined at the Stable Isotope Laboratory of the College of Resources and Environmental Sciences, China Agricultural University, Beijing, China (see details in supplementary materials). These soils were assumed to only contain ${ }^{13} \mathrm{C}$ contained in AM fungal extraradical hyphae or released by the hyphae to the soil.

\section{Collection of extraradical mycelia from hyphal compartment}

Five hundred $g$ of the soil, glass beads, and associated fungal material in the hyphal compartments were transferred to a sieve with a $30 \mu \mathrm{m}$ mesh. The soil was carefully washed through the mesh with filtered sterile deionized water, leaving the extraradical mycelium and glass beads on the sieve. To separate the extraradical mycelia from the glass beads and to clean them, the mixture was transferred into a $1 \mathrm{~L}$ beaker and filtered sterile deionized water was added, before the mixture was stirred and poured back into the sieve, leaving the glass beads in the beaker. This procedure was repeated five times. The extraradical mycelia were rinsed with filtered sterile deionized water before they 
were collected from the sieve using forceps and placed into a microcentrifuge tube. All mycelia samples were weighed before DNA extraction and afterwards stored at $-80^{\circ} \mathrm{C}$ until further processing.

For the non-mycorrhizal treatments, no extraradical hyphae were observed in the hyphal compartment when samples were collected as described above. $0.5 \mathrm{~g}$ residual soil particles on the sieve were collected and referred to as non-mycorrhizal samples. These samples were also stored at $-80^{\circ} \mathrm{C}$ before DNA extraction and tagged as NM (non-mycorrhizal treatment).

\section{DNA extraction, density gradient centrifugation and q-PCR analysis}

DNA of AM fungal mycelia and soil sample collected from last step were extracted using the FastDNA SPIN Kit (MP Biomedicals LLC, Santa Ana, CA, USA) following the manufacturer's instructions. All the extracted rDNA samples (approximately 500 ng) were fully blended with cesium trifluoroacetate (CsTFA) to achieve an initial buoyant density (BD) of $1.560 \mathrm{~g} \mathrm{ml}^{-1}$ before ultracentrifugation at $45400 \mathrm{rpm}$ for $36 \mathrm{~h}$ [46]. The centrifuged gradients were fractionated from bottom to top into 16 equal fractions. The buoyant density of DNA in the gradient fractions was determined using a digital refractometer (Reichert AR2000). The DNA fractions were then purified with isopropyl alcohol and $70 \%(\mathrm{v} / \mathrm{v})$ ethanol and stored at $-80^{\circ} \mathrm{C}$ for further analysis. DNA from each gradient fraction of all treatments was quantified in triplicate by real-time qPCR in an q-TOWER q-PCR analyzer (Jena, Germany) with primers Ba519f/Ba907r (Table S4) using the protocol described in the supplementary material.

\section{S rRNA gene-based Miseq sequencing}

Fractions which had buoyant density of approximately 1.58 were quality checked, and then the DNA samples were sent to the Majorbio Biotechnology Company (Shanghai, China) for sequencing on an Illumina MiSeq (PE300) sequencing platform. 
The V3-V4 hypervariable regions of $16 \mathrm{~S}$ rDNA were amplified using a primer set Ba338f/Ba806r (Table S4). The DNA samples from the NM control soil were sent for sequencing and used as the original soil microbiome community. The DNA samples of $\mathrm{AM}$ fungal mycelia were considered as hyphosphere microbiome. In addition, ${ }^{12} \mathrm{C}$ labeled samples were sequenced and used as the whole hyphosphere microbiome, while ${ }^{13} \mathrm{C}$ labeled samples were used as the active hyphosphere microbiome which influenced by hyphal exudates directly.

\section{Processing of sequencing data}

The Quantitative Insights Into Microbial Ecology (QIIME, v1.8.0) pipeline was used to process the sequencing data, as described previously [47]. The raw sequencing reads were identified to operational taxonomic units (OTUs) according to the methods in supplementary material. The sequences obtained in this study were deposited in the GenBank database under accession number PRJNA556534.

\section{Statistical analysis}

Split-root experiment data from two experiments were analyzed separately. Data from F.m and G.m HCs in Exp 1 or R.i and G.m HC in Exp 2 were compared to determine the difference between different AM fungal species. Data from nonmycorrhiza (NM) control was also compared with F.m and G.m in Exp 1 or R.i and G.m in Exp 2 to determine the effect of AM fungal inoculation. Before ANOVA, AM fungi DNA copy number was used to assess mycorrhizal colonization rate and log-10 transformed. Likewise, the data for the relative abundance of ${ }^{13} \mathrm{C}$ in $\mathrm{HC}$ soil, taxa groups (phyla and genera) and Cluster of Ortholog Genes (COG) functional pathways were arcsine- transformed. SPSS 21.0 (Statistical Product and Service Solutions, IBM, the USA) was employed to conduct above analysis.

Shoot biomass, $\mathrm{P}$ concentration and content data were analyzed separately for the 
$\mathrm{NM}$ or $\mathrm{AM}(F . m / G . m$ or R.i/G.m) as the treatment factor. A posteriori comparison was made using Turkey tests $(P<0.05)$ by SPSS v16.0. SPSS 21.0 (Statistical Product and Service Solutions, IBM, the USA) was employed to conduct above analysis. (version 7.0, http://drive5.com /uparse/). The sequencing results of the ${ }^{13} \mathrm{CO}_{2}$ pulse labeling samples were used to stand for the active hyphosphere microbial community. Bray-curtis distances of $16 \mathrm{~S}$ rRNA genes in nonmetric Principal Component Analysis (PCA) was calculated by QIIME software, then analyzed by vegan package in $\mathrm{R}$ (v 2.4.2) to compare the $\beta$-diversity of each experiment. Significance of the data was estimated using Adonis with $P<0.05$ by vegan package in $\mathrm{R}$ (v 2.4.2). COG information corresponding to Greengene id), and the COG family information corresponding to each OTU through Greengene id corresponding to each OTU for functional prediction obtained.

\section{Acknowledgements}

of China (U1703232) and National Key R\&D Program of China (2017YFD0200200).

TS George contribution through The James Hutton Institute was supported by funds from the Rural and Environment Science and Analytical Services Division of the Scottish Government.

\section{Additional file}

Real time q-PCR analysis protocol;

${ }^{13} \mathrm{C}$ DNA stable isotope probing (SIP) analysis;

$572 \quad$ Processing of pyrosequencing data; 
$573 \quad$ Fig. S1 Root growth system and ${ }^{13} \mathrm{CO}_{2}$ isotope probing equipment;

$574 \quad$ Fig. S2 Photograph before harvesting;

575 Fig. S3 Quantitative distribution of density-resolved bacterial 16S rRNA genes 576 obtained from hyphospheres of different inoculation treatments after a 7-day labeling 577 period with ${ }^{13} \mathrm{CO}_{2}$ and ${ }^{12} \mathrm{CO}_{2}$;

578 Fig. S4 Rarefaction curves of the sequences;

579 Fig. S5 Taxonomic assignment of sequence data at the phylum level;

580 Fig. S6 The Principal Component Analysis (PCA) of 16S rDNA from all 30 samples;

581 Table S1. The physicochemical properties of the soil used in this study;

$582 \quad$ Table S2. Basal mineral nutrients added to the soil;

583 Table S3. Arbuscular mycorrhizal inoculation treatments and inoculum filtrates 584 supplied to RCs;

585 Table S4. Details of primers used in this experiment;

586 Table S5. The relative abundance (\%) of phosphate solubilizing bacteria (PSB) 587 referred to previous studies;

588 Table S6. The relative abundance (\%) of mycorrhizal helper bacteria (MHB) referred 589 to previous studies;

\section{$590 \quad$ Reference}

\section{$591 \quad$ Acknowledgements}

$592 \quad$ Not applicable

\section{$593 \quad$ Funding}

596 TS George contribution through The James Hutton Institute was supported by funds 597 from the Rural and Environment Science and Analytical Services Division of the 
Scottish Government.

\section{Availability of data and materials}

600 The Illumina MiSeq sequence datasets are available at the NCBI Sequence Read 601 Archive BioProject ID PRJN556534.

\section{Authors' contributions}

603 G Feng, XF Chai and JC Zhou designed the study. JC Zhou and XF Chai performed 604 the plant culture and chemical analysis. JC Zhou prepared samples for amplicon 605 sequencing and performed bioinformatics and statistical analyses. JC Zhou, L Zhang, G Feng, TS George contributed to statistical interpretation of results and wrote the manuscript. All authors read and approved the final manuscript.

608 Ethics approval and consent to participate

$609 \quad$ Not applicable.

610 Consent for publication

$611 \quad$ Not applicable.

$612 \quad$ Competing interests

613 The authors declare that they have no competing interests.

614 Publisher's Note

615 Springer Nature remains neutral with regard to jurisdictional claims in 616 published maps and institutional affiliations.

\section{Reference}

[1] Redecker D, Kodner RB, Graham LE. Glomalean Fungi from the Ordovician. Science. 2000;289:1920-1921.

[2] Smith S, Read D. Mycorrhizal Symbiosis, 3rd edn. Academic Press, Amsterdam; 2008. 
[3] Bonfante P, Anca I. Plants, Mycorrhizal Fungi, and Bacteria: A Network of Interactions. Annu Rev Microbiol. 2009;63:363-383.

[4] Kaiser C, Kilburn MR, Clode PL, Fuchslueger L, Koranda M, Cliff JB, Solaiman ZM, Murphy DV. Exploring the transfer of recent plant photosynthates to soil microbes: mycorrhizal pathway vs direct root exudation. New Phytol. 2015;205:1537-1551.

[5] Wang F, Shi N, Jiang R, Zhang FS, Feng G. In situ stable isotope probing of phosphate-solubilizing bacteria in the hyphosphere. J Exp Bot. 2016;67:16891701.

[6] Zhang L, Xu M, Liu Y, Zhang FS, Hodge A, Feng G. Carbon and phosphorus exchange may enable cooperation between an arbuscular mycorrhizal fungus and a phosphate-solubilizing bacterium. New Phytol. 2016;210:1022-1032.

[7] Zhang L, Shi N, Fan J, Wang F, George TS. Feng G. Arbuscular mycorrhizal fungi stimulate organic phosphate mobilization associated with changing bacterial community structure under field conditions. Environ Microbiol. 2018; doi:10.1111/1462-2920.14289.

[8] Scheublin TR, Sanders IR, Keel C, van der Meer JR. Characterization of microbial communities colonizing the hyphal surfaces of arbuscular mycorrhizal fungi. ISME J. 2010;4:752-763.

[9] Garbaye J. Helper bacteria: a new dimension to the mycorrhizal symbiosis (Tansley Review, 76). New Phytol. 1994;128:197-210.

[10] Artursson V, Finlay RD, Jansson JK. Interactions between arbuscular mycorrhizal fungi and bacteria and their potential for stimulating plant growth. Environ Microbiol. 2006;8:1-10.

[11] Singh BK, Nunan N, Ridgway KP, McNicol J, Young JP, Daniell TJ, Prosser JI, Millard P. Relationship between assemblages of mycorrhizal fungi and bacteria on grass roots. Environ Microbiol. 2008;10:534-41.

[12] Vandenkoornhuyse P. Extensive Fungal Diversity in Plant Roots. Science. 2002;295:2051-2051.

[13] Clapp JP, Fitter AH, Young JPW. Ribosomal small subunit sequence variation 
within spores of an arbuscular mycorrhizal fungus, Scutellospora sp. Mol Ecol. 1999;8:915-922.

[14] Redecker D, Schüßler A, Stockinger H, Stürmer SL, Morton JB, Walker C. An evidence-based consensus for the classification of arbuscular mycorrhizal fungi (Glomeromycota). Mycorrhiza. 2013;23:515-531.

[15] Thonar C, Schnepf A, Frossard E, Roose T, Jansa J. Traits related to differences in function among three arbuscular mycorrhizal fungi. Plant Soil. 2011;339:231-245.

[16] Morin E, Miyauchi L, San Clemente H, Chen ECH, Pelin A, de la Providencia I, Ndikumana S, Beaudet D, Hainaut M, Drula E, Kuo A, Tang N, Roy S, Viala J, Henrissat B, Grigoriev IV, Corradi N, Roux C, Martin FM. Comparative genomics of Rhizophagus irregularis, $R$. cerebriforme, $R$. diaphanus and Gigaspora rosea highlights specific genetic features in Glomeromycotina. New Phytol. 2019;222:1584-1598.

[17] Boddington CL, Dodd JC. Evidence that differences in phosphate metabolism in mycorrhizas formed by species of Glomus and Gigaspora might be related to their life-cycle strategies. New Phytol. 1999;142:531-538.

[18] Kiers ET, Duhamel M, Beesetty Y, Mensah JA, Franken O, Verbruggen E, Fellbaum CR, Kowalchuk GA, Hart MM, Bago A, Palmer TM, West SA, Vandenkoornhuyse P, Jansa J, Bücking H. Reciprocal rewards stabilize cooperation in the mycorrhizal symbiosis. Science. 2011;333:880-882.

[19] Toljander JF, Artursson V, Paul LR, Jansson JK, Finlay RD. Attachment of different soil bacteria to arbuscular mycorrhizal fungal extraradical hyphae is determined by hyphal vitality and fungal species. FEMS Microbiol Lett. 2006;254:34-40.

[20] Schnepf A, Roose T, Schweiger P. Growth model for arbuscular mycorrhizal fungi. J R Soc Interface. 2008;5:773-784.

[21] Balzergue C, Puechpages V, Becard G, Rochange SF. The regulation of arbuscular mycorrhizal symbiosis by phosphate in pea involves early and systemic signalling events. J Exp Bot. 2011;62:1049-1060.

[22] Bever JD, Richardson S, Lawrence BM, Holmes J, Watson MA. Preferential 
allocation to beneficial symbiont with spatial structure maintains mycorrhizal mutualism. Ecol Lett. 2009;12:13-21.

[23] Vandenkoornhuyse P, Stéphane M, Ineson P, Staddon P, Ostle N, Cliquet JB, Cliquet AJ, Fitter AH, Young JPW. Active root-inhabiting microbes identified by rapid incorporation of plant-derived carbon into RNA. P Nat Acad Sci USA. 2007; 104:16970-16975.

[24] Trouvelot A, Kough JL, Gianinazzi-Pearson VMesure du taux de mycorhization VA d'un système radiculaire. Recherche de méthodes d'estimation ayant une signification fonctionnelle. In: Physiological and Genetical Aspects of Mycorrhizae, V. Gianinazzi-Pearson and S. Gianinazzi (eds.). INRA Press, Paris, 1986. pp. 217-221.

[25] Staddon PL, Ramsey CB, Ostle NJ, Ineson P, Fitter AH. Rapid Turnover of Hyphae of Mycorrhizal Fungi Determined by AMS Microanalysis of ${ }^{14} \mathrm{C}$. Science. 2003;300:1138-1140.

[26] Nuccio EE, Hodge A, Pett-Ridge J, Herman DJ, Weber PK, Firestone, MK. An arbuscular mycorrhizal fungus significantly modifies the soil bacterial community and nitrogen cycling during litter decomposition. Environ Microbiol. 2013;15:1870-1881.

[27] Wang F, Kertesz MA, Feng G. Phosphorus forms affect the hyphosphere bacterial community involved in soil organic phosphorus turnover. Mycorrhiza. 2019; doi:10.1007/s00572-019-00896-0.

[28] Michiel V, Wolf A B, Jennings SJ, Kowalchuk GA. Micro-scale determinants of bacterial diversity in soil. FEMS Microbiol Rev. 2013;37:936-954.

[29] Bottomley PJ. Microbial activity in soil. Curr Opin Biotech. 1993;4:318-322.

[30] Young IM, Crawford JW. Interactions and Self-Organization in the Soil-Microbe Complex. Science. 2004;304:1634-1637.

[31] Hodge A, Fitter AH. Substantial nitrogen acquisition by arbuscular mycorrhizal fungi from organic material has implications for N cycling. P Nat Acad Sci USA. 2010;107:13754-13759.

[32] Jansa J, Mozafar A, Kuhn G, Anken T, Ruh R, Sanders IR, Frossard E. Soil tillage affects the community structure of mycorrhizal fungi in maize roots. Ecol Appl. 2003;13:1164-1176. 
[33] George TS, Richardson AE, Li SS, Gregory PJ, Daniell TJ. Extracellular release of a heterologous phytase from roots of transgenic plants: does manipulation of rhizosphere biochemistry impact microbial community structure? FEMS Microbiol Ecol. 2009;70:433-45.

[34] Cheng C, Lim BL. Beta-propeller phytases in the aquatic environment. Arch Microbiol. 2006;185:1-13.

[35] Bukovska P, Bonkowski M, Konvalinkova T, Beskid O, Hujslova M, Puschel D, Rezacova V, Gutierrez-Nunez SM, Gryndler M, Jansa J. Utilization of organic nitrogen by arbuscular mycorrhizal fungi-is there a specific role for protists and ammonia oxidizers? Mycorrhiza. 2018;28:269.

[36] Freyklett P, Garbaye J, Tarkka MT. The mycorrhiza helper bacteria revisited. New Phytol. 2007;176:22-36.

[37] Garbaye J, Duponnois R. Specificity and Function of Mycorrhization Helper Bacteria (MHB) Associated with the Pseudotsuga menziesii - Laccaria laccata Symbiosis. Symbiosis. 1993;14:335-344.

[38] Abdelfattah GM, Mohamedin AH. Interactions between a vesicular-arbuscular mycorrhizal fungus (Glomus intraradices) and Streptomyces coelicolor and their effects on sorghum plants grown in soil amended with chitin of brawn scales. Biol Fert Soils. 2000;32:401-409.

[39] Keller S, Schneider K, Sussmuth RD. Structure elucidation of auxofuran, a metabolite involved in stimulating growth of fly agaric, produced by the mycorrhiza helper bacterium Streptomyces AcH 505. Journal of Antibiot. 2006;59:801-803.

[40] Choi J, Yang F, Stepanauskas R, Cardenas E, Garoutte A, Williams R, Flater J, Tiedje JM, Hofmockel KS, Gelder B, Howe A. Strategies to improve reference databases for soil microbiomes. ISME J. 2017;4:829-834.

[41] Zhang L, Feng G, Declerck S. Signal beyond nutrient, fructose, exuded by an arbuscular mycorrhizal fungus triggers phytate mineralization by a phosphate solubilizing bacterium. ISME J. 2018; doi:10.1038/s41396-018-0171-4.

[42] Wang F, Jiang R, Kertesz MA, Zhang FS, Feng G. Arbuscular mycorrhizal fungal hyphae mediating acidification can promote phytate mineralization in the hyphosphere of maize (Zea mays L.). Soil Biol Biochem. 2013;65:69-74. 
[43] Bernacchi CJ, Calfapietra C, Davey P A, Wittig VE, Scarascia-Mugnozza GE, Raines CA, Long SP. Photosynthesis and stomatal conductance responses of poplars to free-air $\mathrm{CO}_{2}$ enrichment (PopFACE) during the first growth cycle and immediately following coppice. New Phytol. 2003;159(3):609-621.

[44] Thomas RL, Sheard RW, Moyer JR. Comparison of conventional and automated procedures for nitrogen, phosphorus, and potassium analysis of plant material using a single digestion. Agron J. 1967;59:240-243.

[45] Jakobsen I, Abbott LK, Robson AD. External hyphae of vesicular-arbuscular mycorrhizal fungi associated with Trifolium subterraneum L. 1. Spread of hyphae and phosphorus inflow into roots. New Phytol. 1992;120:371-380.

[46] Whiteley AS, Thomson BC, Lueders T, Manefield M. DNA stable isotope probing. Nat Protoc. 2007;2:838-844.

[47] Caporaso JG, Kuczynski J, Stombaugh J, Bittinger K, Bushman FD, Costello EK, Fierer N, Gonzalez A, Goodrich JK, Gordon JI, Huttley GA, Kelley ST, Knights D, Koenig JE, Ley RE, Lozupone CA, Mcdonald D, Muegge BD, Pirrung M, Reeder J, Rsevinsky JR, Turnbaugh PJ, Walters WA, Widmann J, Yatsunenko T, Zaneveld J, Knight R. QIIME allows analysis of high-throughput community sequencing data. Nat Methods. 2010;7:335-336.

\section{Figure and table legend}

Fig. 1 The experimental design and plant growth system. The host plant was cotton (Gossypium herbaceum L.). RC and HC denote the root compartment and hyphal compartment, respectively. The dotted lines indicate a $30 \mu \mathrm{m}$ nylon mesh and the zone between two meshes was a buffer zone. Exp 1 and Exp 2 refer to two independent experiments. The nonmycorrhizal (NM) control is compared to Rhizophagus intraradices (R.i) (EY108), Funneliformis mosseae (F.m) (MD118) and Gigaspora margarita (G.m) (JA101A), the three different AM fungal inocula. St means sterilized. The information on AM fungal inoculation treatments and inoculum filtrates supplied 
to RCs is shown in the table S3. The brown circles represent the original bacterial community from soil. The red, blue and purple lines represent the hyphae of F.m, G.m and R.i, respectively. While the red, blue and purple circles represent the original bacterial community from F.m, G.m and R.i inoculum, respectively.

Fig. 2 The log AM fungal DNA copy number in the roots of cotton plants (a); hyphal length density (b) and ${ }^{13} \mathrm{C}$ abundance of the HC soil (c). Exp 1 and Exp 2 refer to the two independent experiments. The nonmycorrhizal (NM) control is compared to Rhizophagus intraradices (R.i) (EY108), Funneliformis mosseae (F.m) (MD118) and Gigaspora margarita (G.m) (JA101A), the three different AM fungal inocula. All the treatments showed in this part were ${ }^{13} \mathrm{C}$ labeled. **: $P<0.01, * * *: P<0.001$.

Fig. 3 Phylum level distribution of DNA sequences. Exp 1 and Exp 2 refer to two independent experiments. The three different AM fungal inocula were Rhizophagus intraradices (R.i) (EY108), Funneliformis mosseae (F.m) (MD118) and Gigaspora margarita (G.m) (JA101A). All the treatments shown were ${ }^{13} \mathrm{C}$ labeled. *, ** and ** mean this phylum was in greater abundance in this condition in same experiment in $P<0.05,0.01$ or 0.001 level, respectively.

Fig. 4 Genus level distribution of DNA sequences. The genus showed in this plot were dominant, which occupied over 1\%, others were summed in Others. Exp 1 and Exp 2 refer to two independent experiments. The three different AM fungal inocula were Rhizophagus intraradices (R.i) (EY108), Funneliformis mosseae (F.m) (MD118) and Gigaspora margarita (G.m) (JA101A). All the treatments shown in this part were ${ }^{13} \mathrm{C}$ labeled. *, ** and ${ }^{* *}$ mean this genus was in greater abundance in this condition in same experiment in $P<0.05,0.01$ or 0.001 level, respectively. The red named genus occurred in both AM fungal hyphosphere of same experiment. 
Fig. 5 Venn plot of number and proportion of genera in F.m/G.m of Exp 1 and

800

801

802

803

804

805

806

807

808

809

810

811

812

R.i/G.m of Exp 2. The overlapping area refers to the genera without a significant difference in relative abundance among different inoculation treatments $\left({ }^{13} \mathrm{C}\right.$ samples $)$, while the number and percentage in brackets means the percentage of genera with a significant difference in relative abundance among different inoculation treatments $\left({ }^{13} \mathrm{C}\right.$ samples). The three different AM fungal inocula were Rhizophagus intraradices (R.i) (EY108), Funneliformis mosseae (F.m) (MD118) and Gigaspora margarita (G.m) (JA101A). All the treatments showed in this part were ${ }^{13} \mathrm{C}$ labeled.

Fig. 6 The Principal Component Analysis (PCA) of 16S rRNA genes in Exp 1 (a) and Exp 2 (b). Exp 1 and Exp 2 refer to two independent experiments. The nonmycorrhizal (NM) control is compared to Rhizophagus intraradices (R.i) (EY108), Funneliformis mosseae (F.m) (MD118) and Gigaspora margarita (G.m) (JA101A), the three different AM fungal inocula. The $P$ value in this part was analyzed by permutational MANOVA (eg. adonis).

Fig. 7 Heatmap plot of Cluster of Ortholog Genes (COG) functional pathway relative abundance under in F.m/G.m of Exp 1 and R.i/G.m of Exp 2. The three different AM fungal inocula were Rhizophagus intraradices (R.i) (EY108), Funneliformis mosseae (F.m) (MD118) and Gigaspora margarita (G.m) (JA101A). All the treatments showed in this part were ${ }^{13} \mathrm{C}$ labeled. Different letters mean significant difference between different treatments at $P<0.05$ level.

Table 1 Biomass, Phosphorus (P) concentration and $\mathrm{P}$ content of shoots in different inoculation treatments. 


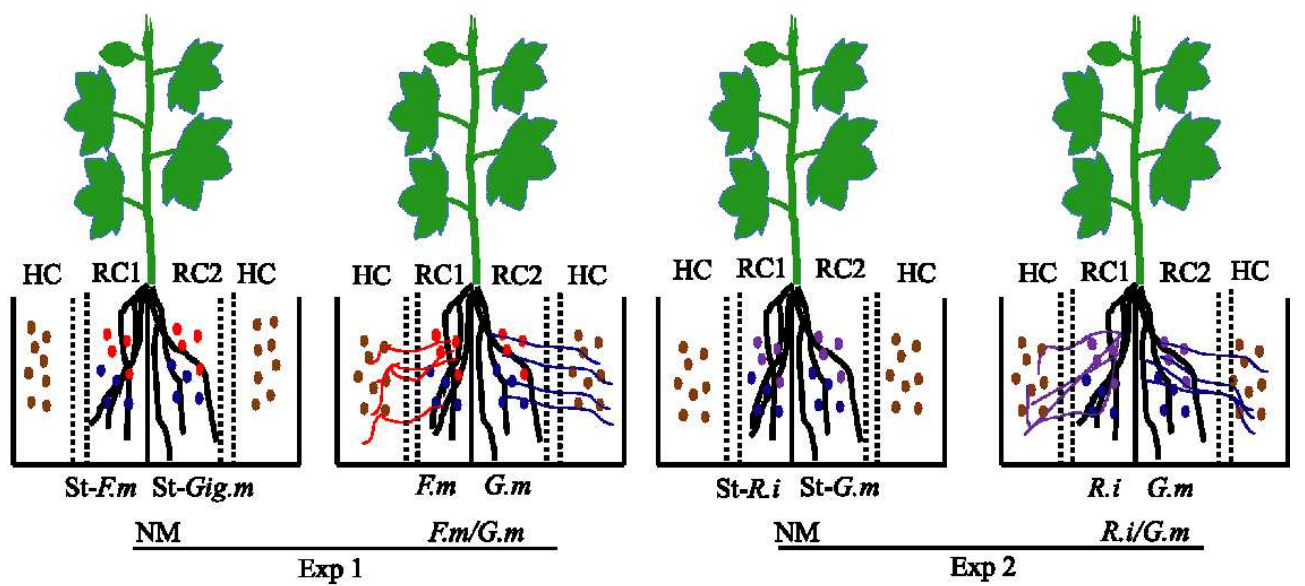

Fig. 1 The experimental design and plant growth system. The host plant was cotton

826 (Gossypium herbaceum L.). RC and $\mathrm{HC}$ denote the root compartment and hyphal 827 compartment, respectively. The dotted lines indicate a $30 \mu \mathrm{m}$ nylon mesh and the zone 828 between two meshes was a buffer zone. Exp 1 and Exp 2 refer to two independent experiments. The nonmycorrhizal (NM) control is compared to Rhizophagus intraradices (R.i) (EY108), Funneliformis mosseae (F.m) (MD118) and Gigaspora margarita (G.m) (JA101A), the three different AM fungal inocula. St means sterilized. The information on AM fungal inoculation treatments and inoculum filtrates supplied 833 to RCs is shown in the table S3. The brown circles represent the original bacterial community from soil. The red, blue and purple lines represent the hyphae of F.m, G.m and R.i, respectively. While the red, blue and purple circles represent the original bacterial community from F.m, G.m and R.i inoculum, respectively. 

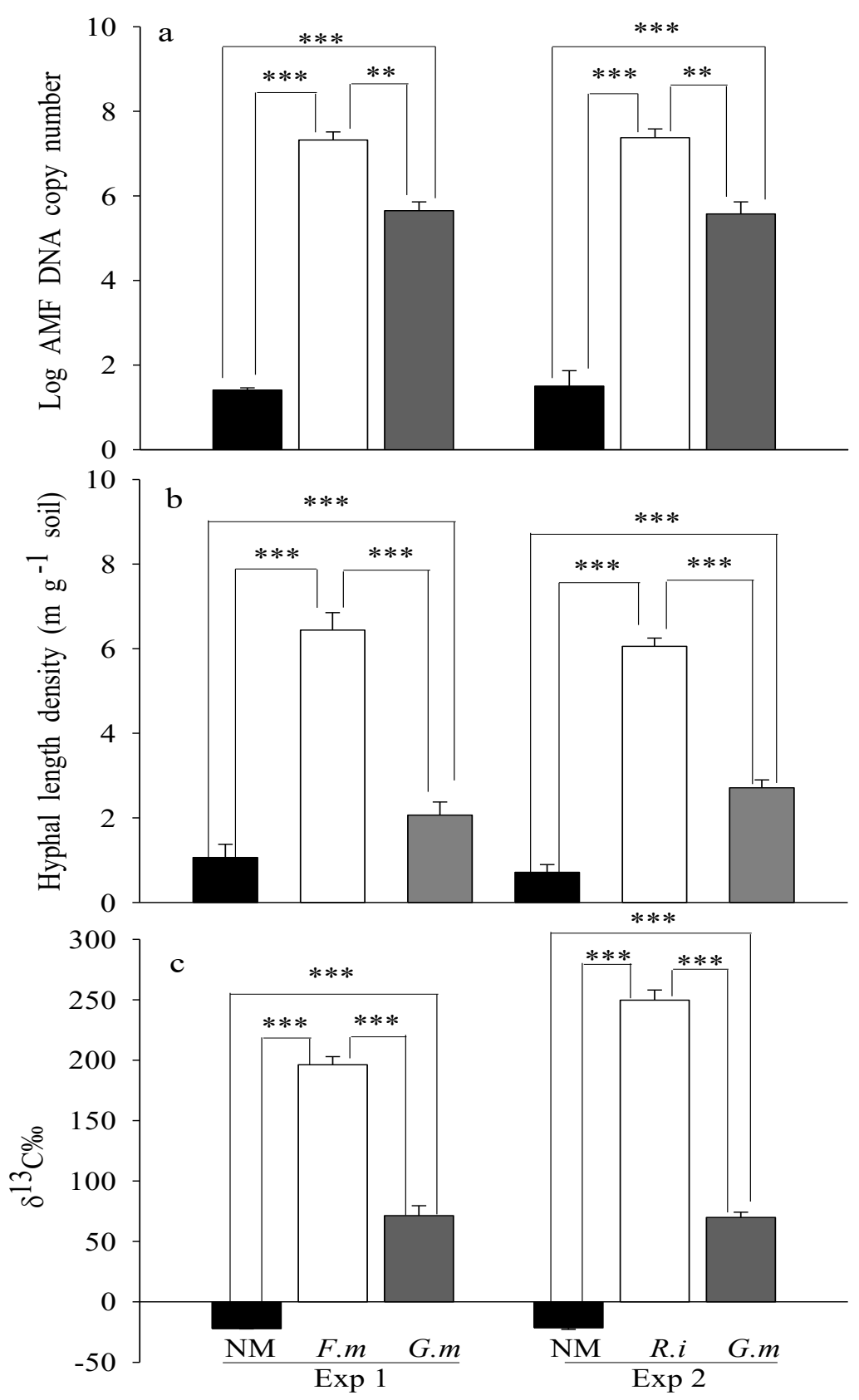

Fig. 2 The $\log$ AM fungal DNA copy number in the roots of cotton plants (a);

842 hyphal length density (b) and ${ }^{13} \mathrm{C}$ abundance of the HC soil (c). Exp 1 and Exp 2 refer 843 to the two independent experiments. The nonmycorrhizal (NM) control is compared to 844 Rhizophagus intraradices (R.i) (EY108), Funneliformis mosseae (F.m) (MD118) and 845 Gigaspora margarita (G.m) (JA101A), the three different AM fungal inocula. All the 846 treatments showed in this part were ${ }^{13} \mathrm{C}$ labeled. $* *: P<0.01, * * *: P<0.001$. 
Exp1-F.m

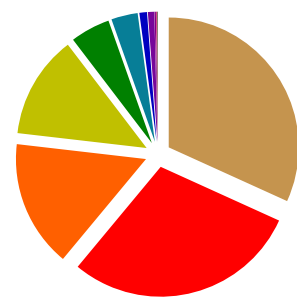

Total $=100$

$\square 31.79 \%$ Actinobacteria*

29.24\% Gemmatimonadetes*

口 $15.81 \%$ Proteobacteria

口 $12.81 \%$ Firmicutes

4.95\% Chloroflexi

a $3.29 \%$ Bacteroidetes

0.94\% Acide

- $0.79 \%$ Planctomycetes*

$0.17 \%$ Nitrospirae

$0.10 \%$ unclassified_k_noran

ㅁ $0.05 \%$ Armatimonadetes

ㅁ $0.01 \%$ Cyanobacteria

口 $0.01 \%$ Fusobacteria

- $0.06 \%$ others

Exp1-G.m

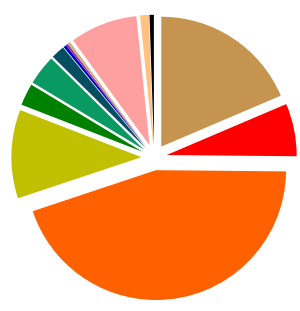

Total $=100$

口 $18.59 \%$ Actinobacteria

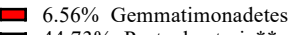
$44.73 \%$ Proteobacteria** ㅁ $11.02 \%$ Firmicutes

口 $2.73 \%$ Chloroflexi

$3.74 \%$ Bacteroidetes

$1.69 \%$ Acidobacteria

$0.38 \%$ Planctomycetes

$0.14 \%$ Nitrospirae

$0.10 \%$ unclassified_k_norank

口 $0.30 \%$ Armatimonadetes**

口 $8.40 \%$ Cyanobacteria**

口 $1.08 \%$ Fusobacteria**

$0.54 \%$ others
Exp2-R.i

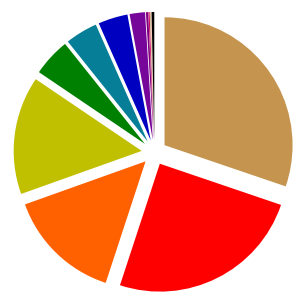

Total $=100$

$\operatorname{Exp} 2-G . m$

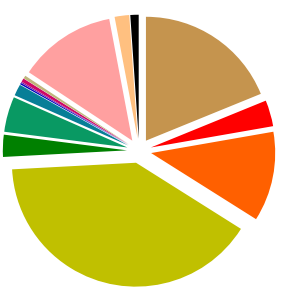

Total $=100$
ב $30.22 \%$ Actinobacteria*

es***

$14.50 \%$ Firmicutes

$14.95 \%$ Proteobacteri

$4.80 \%$ Chloroflexi

口 $4.08 \%$ Bacteroidetes

- $3.73 \%$ Acidobacteria

ㅁ $1.94 \%$ Planctomycetes***

口 $0.29 \%$ Nitrospirae

$0.15 \%$ Armatimonadetes

ㅁ $0.07 \%$ Cyanobacteria

ㅁ $0.02 \%$ Fusobacteria

- $0.34 \%$ Others

Fig. 3 Phylum level distribution of DNA sequences. Exp 1 and Exp 2 refer to two independent experiments. The three different AM fungal inocula were Rhizophagus intraradices (R.i) (EY108), Funneliformis mosseae (F.m) (MD118) and Gigaspora margarita (G.m) (JA101A). All the treatments shown were ${ }^{13} \mathrm{C}$ labeled. ${ }^{*}, * *$ and $* *$ mean this phylum was in greater abundance in this condition in same experiment in $P<0.05,0.01$ or 0.001 level, respectively. 

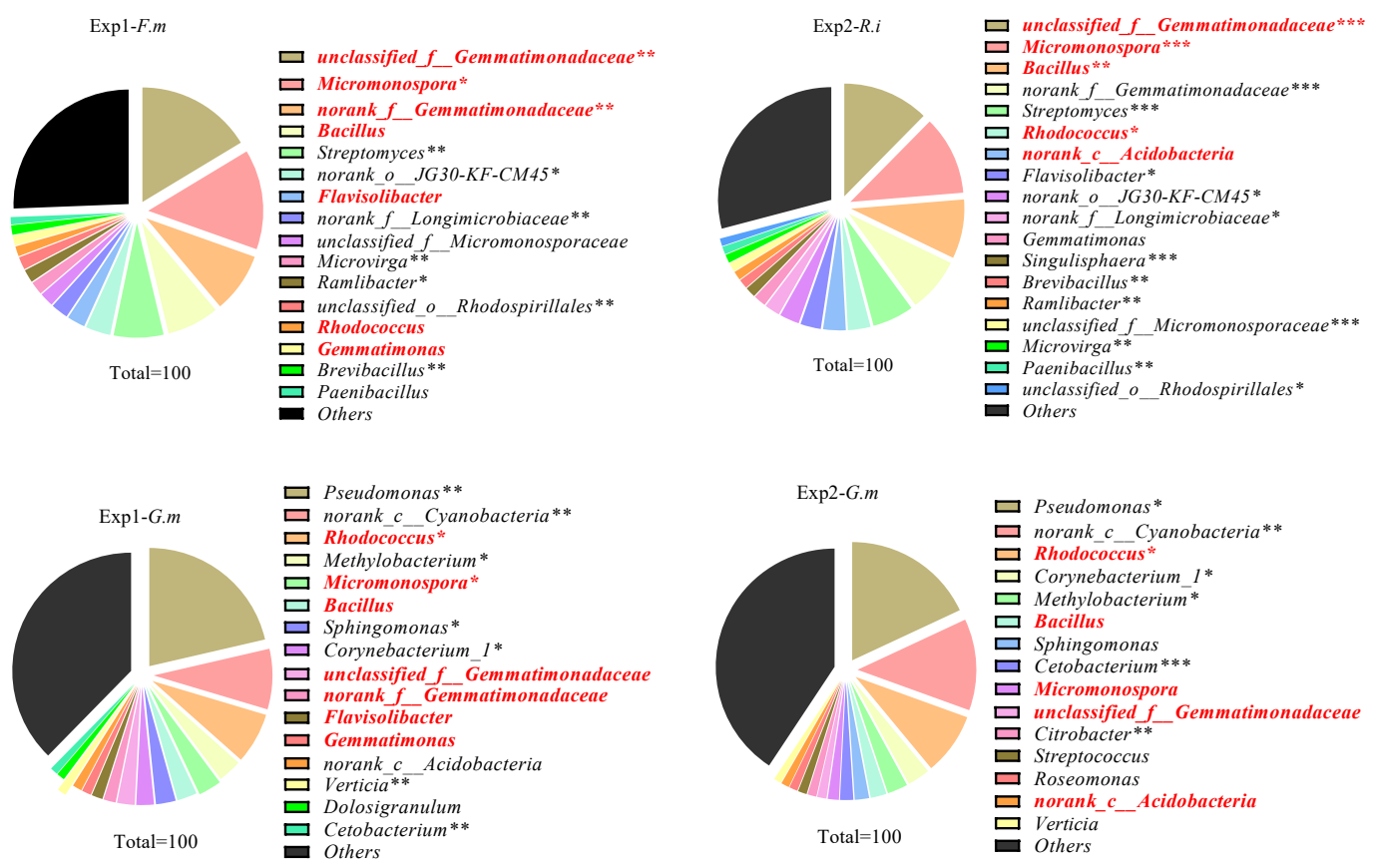

Fig. 4 Genus level distribution of DNA sequences. The genus showed in this plot 856 were dominant, which occupied over 1\%, others were summed in Others. Exp 1 and 857 Exp 2 refer to two independent experiments. The three different AM fungal inocula were Rhizophagus intraradices (R.i) (EY108), Funneliformis mosseae (F.m) (MD118) and Gigaspora margarita (G.m) (JA101A). All the treatments shown in this part were ${ }^{13} \mathrm{C}$ labeled. *, ** and $* *$ mean this genus was in greater abundance in this condition in same experiment in $P<0.05,0.01$ or 0.001 level, respectively. The red named genus occurred in both AM fungal hyphosphere of same experiment. 
875

876

877

878

879

880

881

882

883

884

885

886

887

888

889

890

891

892

893

894

895

896

897

898

899

900

901

902

903

904

905

906

907

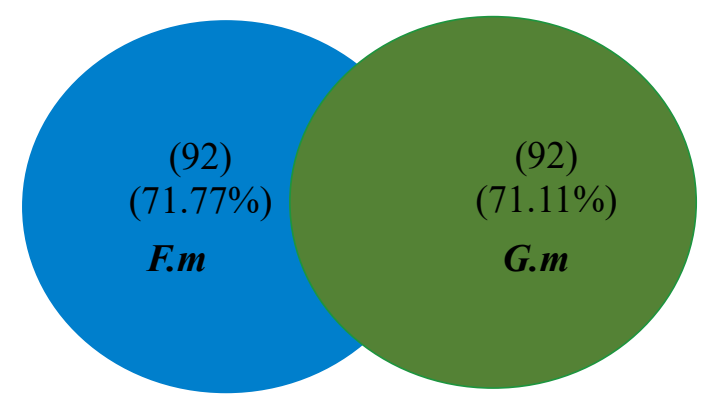

F.m/G.m

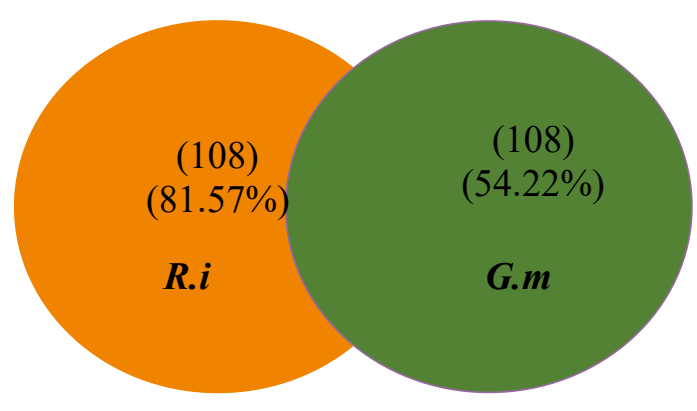

R.i/G.m

Fig. 5 Venn plot of number and proportion of genera in F.m/G.m of Exp 1 and R.i/G.m of Exp 2. The overlapping area refers to the genera without a significant difference in relative abundance among different inoculation treatments $\left({ }^{13} \mathrm{C}\right.$ samples), while the number and percentage in brackets means the percentage of genera with a significant difference in relative abundance among different inoculation treatments $\left({ }^{13} \mathrm{C}\right.$ samples). The three different AM fungal inocula were Rhizophagus intraradices (R.i) (EY108), Funneliformis mosseae (F.m) (MD118) and Gigaspora margarita (G.m) (JA101A). All the treatments showed in this part were ${ }^{13} \mathrm{C}$ labeled. 
(a)

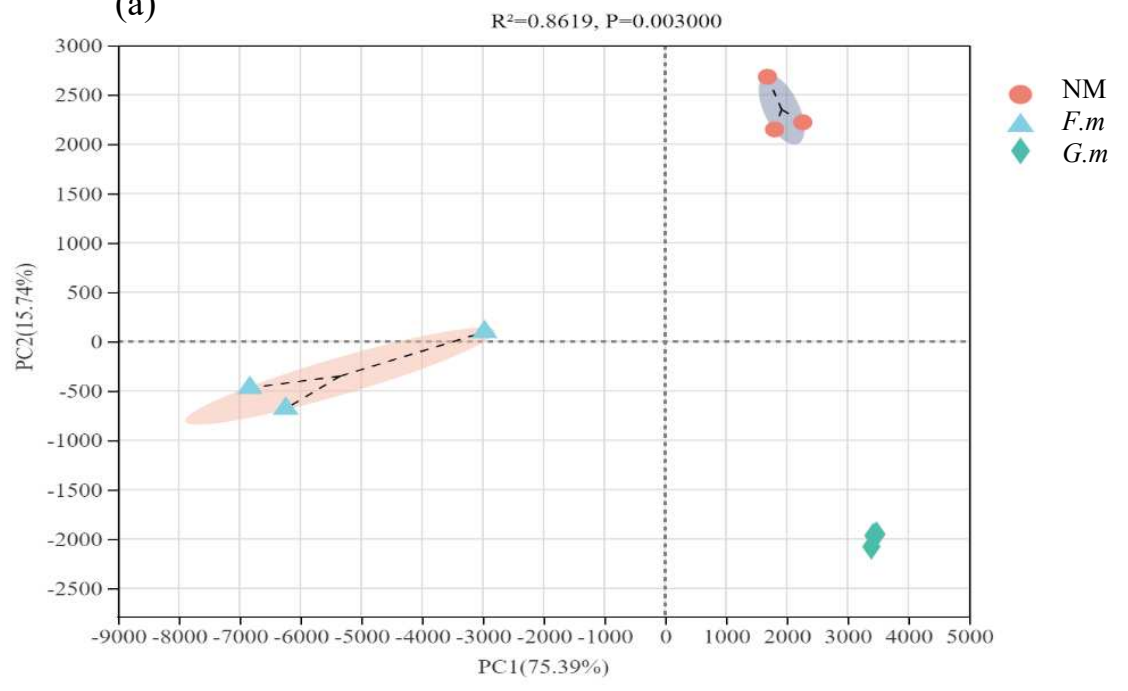

923

924

925

926

927

928

929

930

(b)

$\mathrm{R}^{2}=0.7940, \mathrm{P}=0.005000$

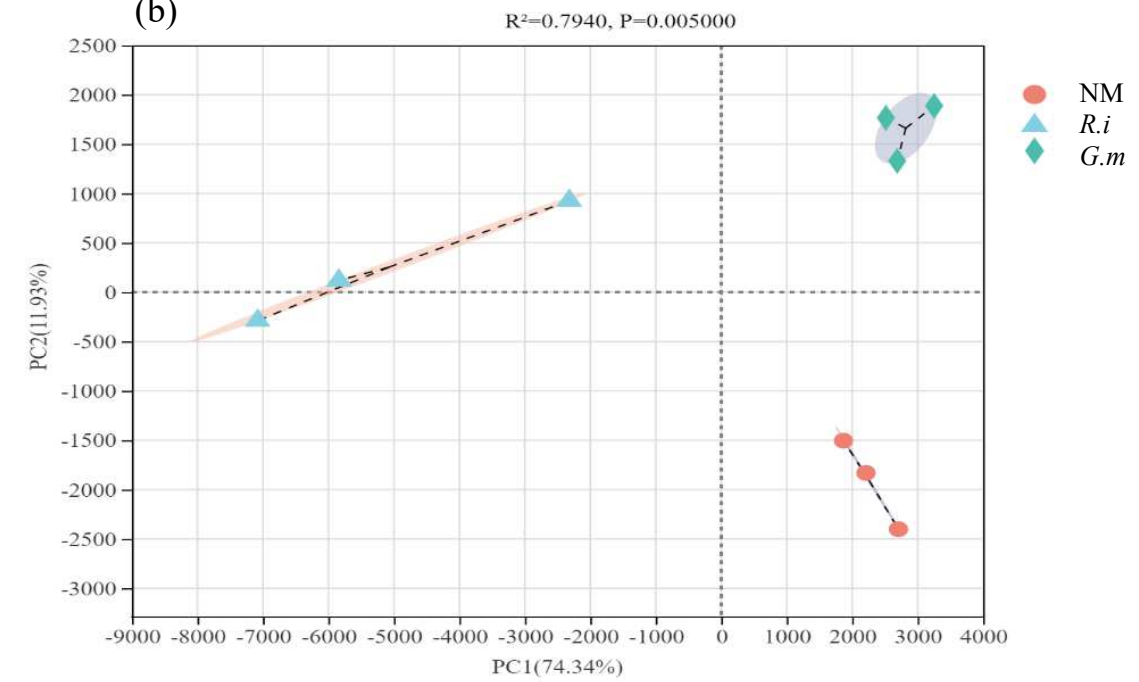

931

Fig. 6 The Principal Component Analysis (PCA) of 16S rRNA genes in Exp 1 (a)

and Exp 2 (b). Exp 1 and Exp 2 refer to two independent experiments. The nonmycorrhizal (NM) control is compared to Rhizophagus intraradices (R.i) (EY108),

Funneliformis mosseae (F.m) (MD118) and Gigaspora margarita (G.m) (JA101A), the permutational MANOVA (eg. adonis). 


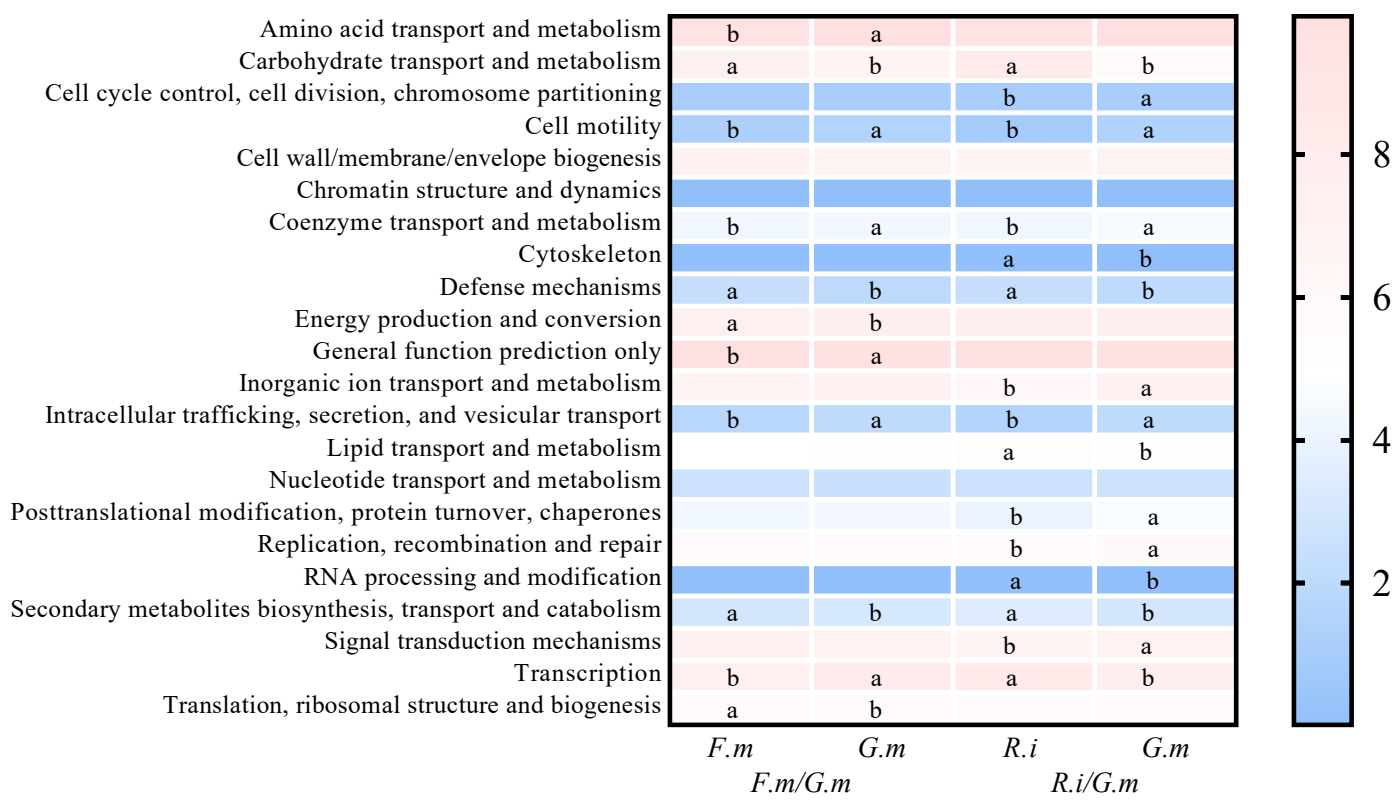

Fig. 7 Heatmap plot of Cluster of Ortholog Genes (COG) functional pathway between different treatments at $P<0.05$ level. 

different inoculation treatments.

\begin{tabular}{ccccc}
\hline \multicolumn{2}{c}{ Conditions } & Biomass $(\mathrm{g})$ & $\mathrm{P}$ concentration $\left(\mathrm{mg} \mathrm{g}^{-1}\right)$ & $\mathrm{P}$ content $\left(\mathrm{mg} \mathrm{plant}^{-1}\right)$ \\
\hline \multirow{2}{*}{ Exp 1 } & $\mathrm{NM}$ & $0.82 \pm 0.06$ & $0.91 \pm 0.04$ & $0.74 \pm 0.05$ \\
& F.m $/ G . m$ & $5.93 \pm 0.25 * *$ & $1.49 \pm 0.06 *$ & $8.84 \pm 0.47 * * *$ \\
\multirow{2}{*}{ Exp 2 } & $\mathrm{NM}$ & $0.79 \pm 0.06$ & $0.87 \pm 0.07$ & $0.67 \pm 0.04$ \\
& R.i $/$ G.m & $5.78 \pm 0.30 * *$ & $1.92 \pm 0.09 * *$ & $11.03 \pm 0.59 * * *$
\end{tabular}

959 Note: Exp 1 and Exp 2 refers to two independent experiments. The nonmycorrhizal 960 (NM) control is compared to Rhizophagus intraradices (R.i) (EY108), Funneliformis 961 mosseae (F.m) (MD118) and Gigaspora margarita (G.m) (JA101A), the three different 962 AM fungal inocula. All the treatments shown in this part were ${ }^{13} \mathrm{C}$ labeled. The values 963 in the tables were mean value, and *: $P<0.05, * *: P<0.01, * * *: P<0.001$. 
Figures
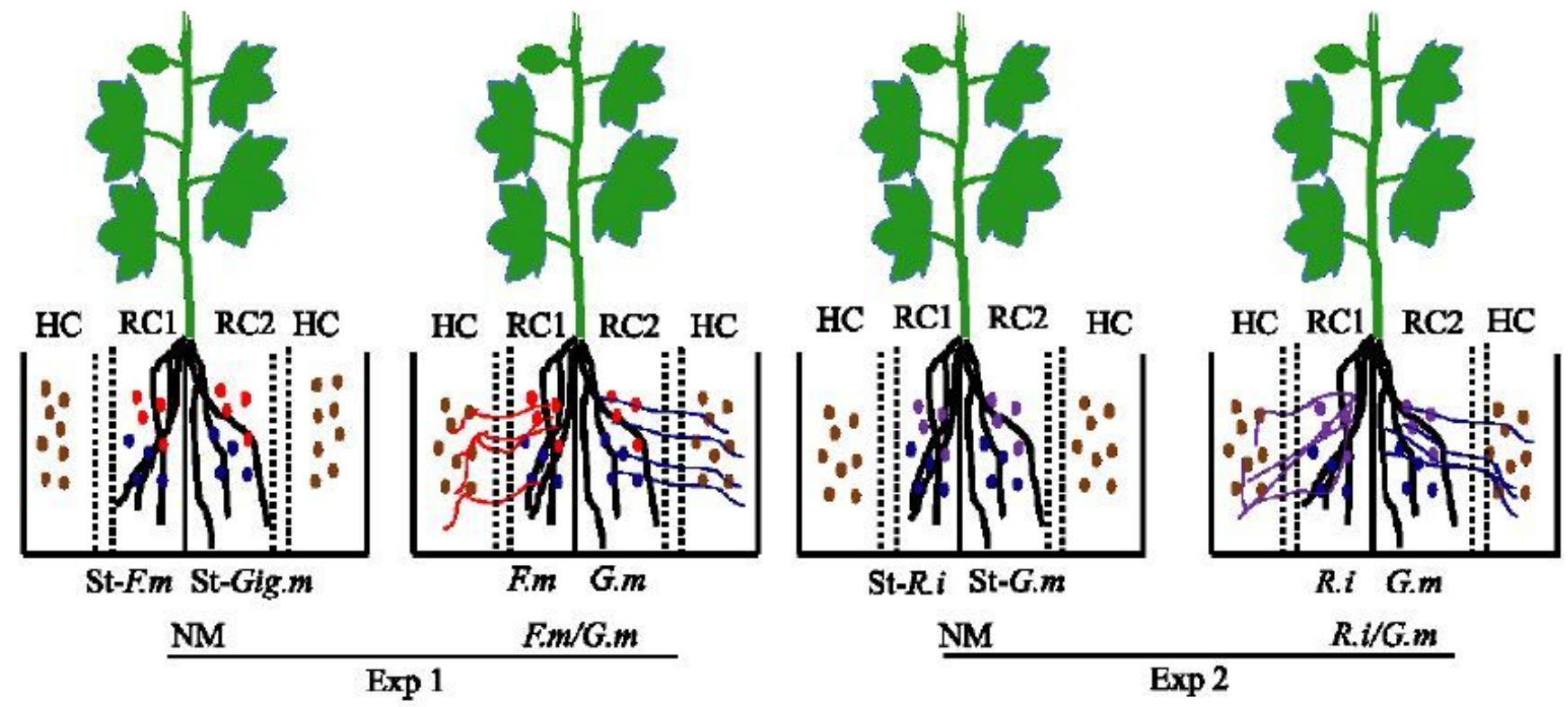

Figure 1

Figure 1 

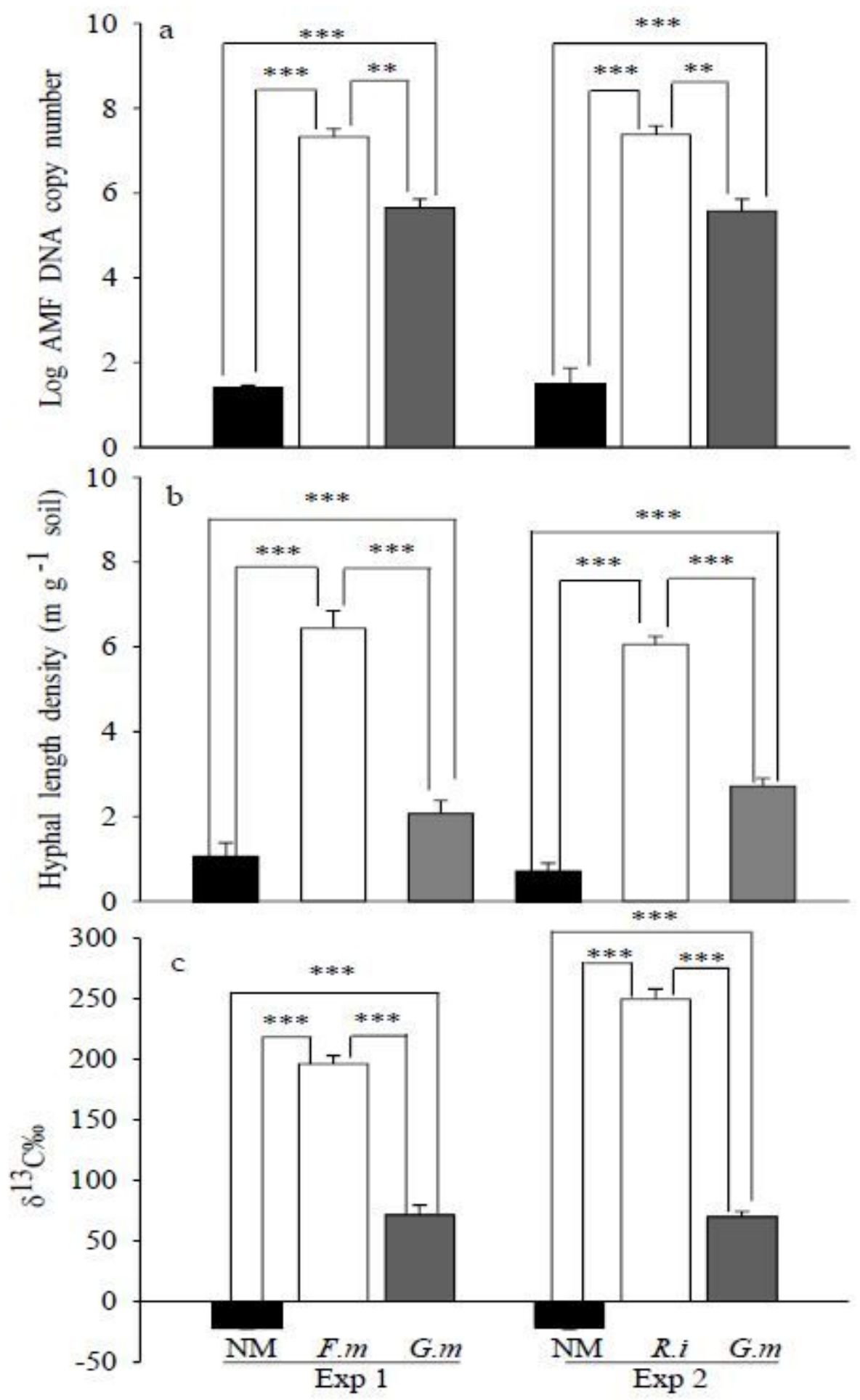

Figure 2

Figure 2 


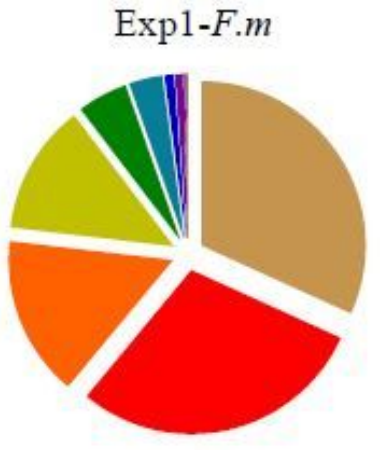

Total $=100$
口 $31.79 \%$ Actinobacteria* 口 $29.24 \%$ Gemmatimonadetes** $\square \quad 15.81 \%$ Proteobacteria 口 $12.81 \%$ Firmicutes 口 $4.95 \%$ Chloroflexi 口 $3.29 \%$ Bacteroidetes - $0.94 \%$ Acidobacteria - $0.79 \%$ Planctomycetes* च $0.17 \%$ Nitrospirae 口 $0.10 \%$ unclassified_k_norank 口 $0.05 \%$ Armatimonadetes 口 $0.01 \%$ Cyanobacteria 口 $0.01 \%$ Fusobacteria - $0.06 \%$ others

Exp1-G.m

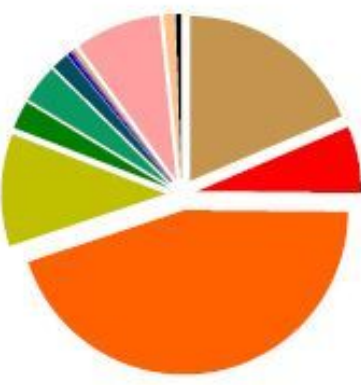

Total $=100$

口 $1.08 \%$ Fusobacteria**

$\square$
$6.56 \%$ Gemmatimonadetes
$44.73 \%$ Proteobacteria**
$11.02 \%$ Firmicutes
$\square .73 \%$ Chloroflexi
$3.74 \%$ Bacteroidetes
$\square$
$1.69 \%$ Acidobacteria
$0.38 \%$ Planctomycetes
$0.14 \%$ Nitrospirae
$0.10 \%$ unclassified_k_norank
$\square 0.30 \%$ Armatimonadetes**
$\square .40 \%$ Cyanobacteria**
$\square \quad 1.08 \%$ Fusobacteria**
$0.54 \%$ others

$\square$ $\square 44.73 \%$ Proteobacteria**

$\square 2.73 \%$ Chloroflexi

\section{Exp2-R.i}

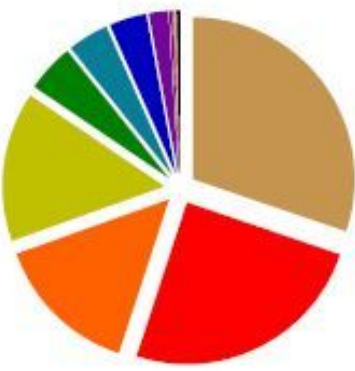

Total $=100$

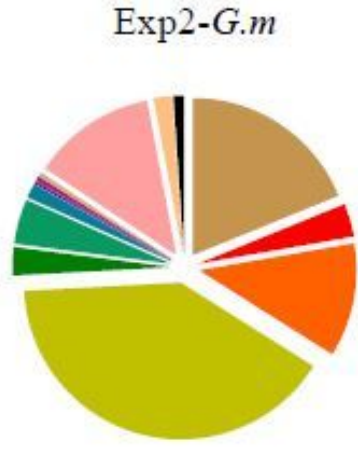

Total $=100$ $\square 30.22 \%$ Actinobacteria* ㅁ $24.82 \%$ Gemmatimonadetes*** 口 $14.50 \%$ Firmicutes ㅁ $14.95 \%$ Proteobacteria ㅁ. $4.80 \%$ Chloroflexi $\square \quad 4.08 \%$ Bacteroidetes - $3.73 \%$ Acidobacteria - $1.94 \%$ Planctomycetes*** D $0.29 \%$ Nitrospirae 口 $0.15 \%$ Armatimonadetes 口 $0.07 \%$ Cyanobacteria 口 $0.02 \%$ Fusobacteria

- $0.34 \%$ Others

\section{Figure 3}

Figure 3

$\square 18.83 \%$ Actinobacteria - $3.42 \%$ Gemmatimonadetes $\square 11.72 \%$ Firmicutes $\square 40.19 \%$ Proteobacteria* $2.88 \%$ Chloroflexi प $4.61 \%$ Bacteroidetes $\square 1.49 \%$ Acidobacteria - $0.20 \%$ Planctomycetes $0.13 \%$ Nitrospirae $0.46 \%$ Armatimonadetes $\square 0.39 \%$ Verrucomicrobia** 口 $12.71 \%$ Cyanobacteria** $\square 1.90 \%$ Fusobacteria** - $1.08 \%$ Others
- $0.54 \%$ others

Total=100 
Expl-F.m

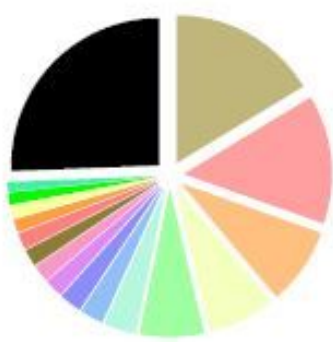

Total $=100$

Total $=100$

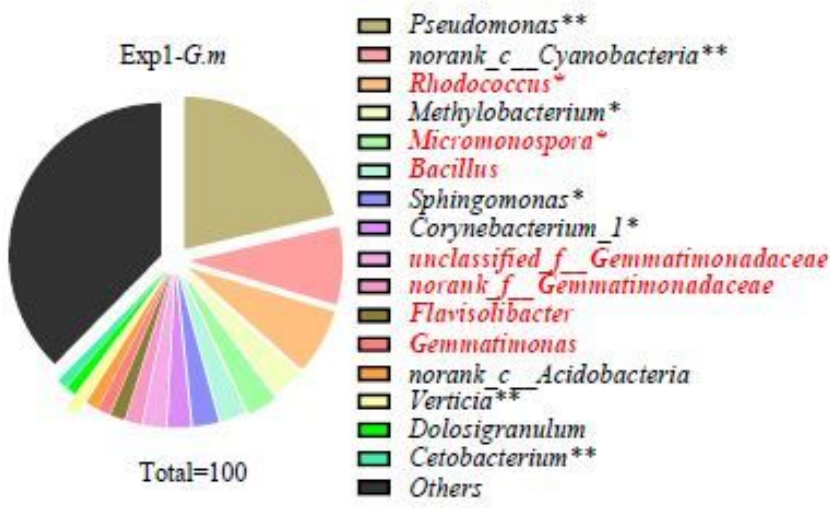

$\square$ unclassified_f__Gemmatimonadaceae

$\square$ Micromonospora

$\square$ norank $f$ Gemmatimonadaceae

$\square$ Bacillus

$\square$ Streptomyces**

$\square$ norank_o JG30-KF-CM45*

$\square$ Flavisolibacter

$\square$ norank_f_Longimicrobiaceae* *

$\square$ unclassified_f_Micromonosporaceae

$\square$ Microvirga**

$\square$ Ramlibacter*

$\square$ unclassified_o__Rhodospirillales**

$\square$ Rhodococcus

$\square$ Gemmatimonas

$\square$ Brevibacillus**

$\square$ Paenibacillus

- Others

Figure 4

Figure 4

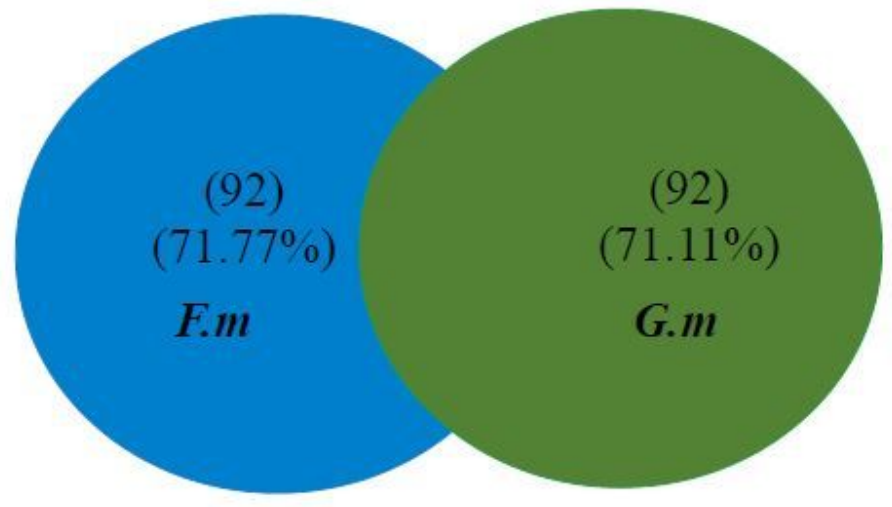

F.m/G.m

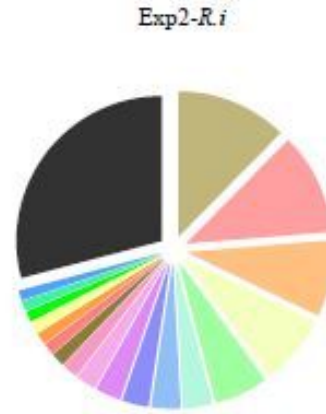

Total $=100$

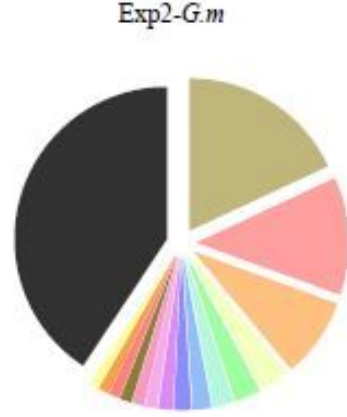

Total $=100$ $\square$ unclassified $f$ Gemmatimonadaceae

$\square$ Micromonospora

$\square$ Bacillus"0

$\square$ norank_f_Gemmatimonadaceae***

$\square$ Streptomyces***

$\square$ Rhodococcus*

$\square$ norank_c_Acidobacteric

$\square$ Flavisolibacter*

$\square$ norank o JG30-KF-CM45*

$\square$ norank_f_Longimicrobiaceae *

$\square$ Gemmatimonas

$\square$ Singulisphaera***

$\square$ Brevibacillus*:

$\square$ Ramlibacter**

$\square$ unclassified_f_Micromonosporaceae***

Microvirga**

口 Paenibacillus**

$\square$ unclassified_o_Rhodospirillales*

Others

$\square$ Pseudomonas*
$\square$ norank_c_Cyanobacteria**
$\square$ Rhodococcus*
$\square$ Corynebacterium_l*
$\square$ Methylobacterium*
$\square$ Bacillus
$\square$ Sphingomonas
$\square$ Cetobacterium***
$\square$ Micromonospora
$\square$ unclassified_f_Gemmatimonadaceae
$\square$ Sitrobacter.*- Streptococcus
$\square$ Roseomonas
$\square$ norank_c_.Acidobacteria
$\square$ Verticia


(a)

$\mathrm{R}^{2}-0.8619, \mathrm{P}-0.003000$

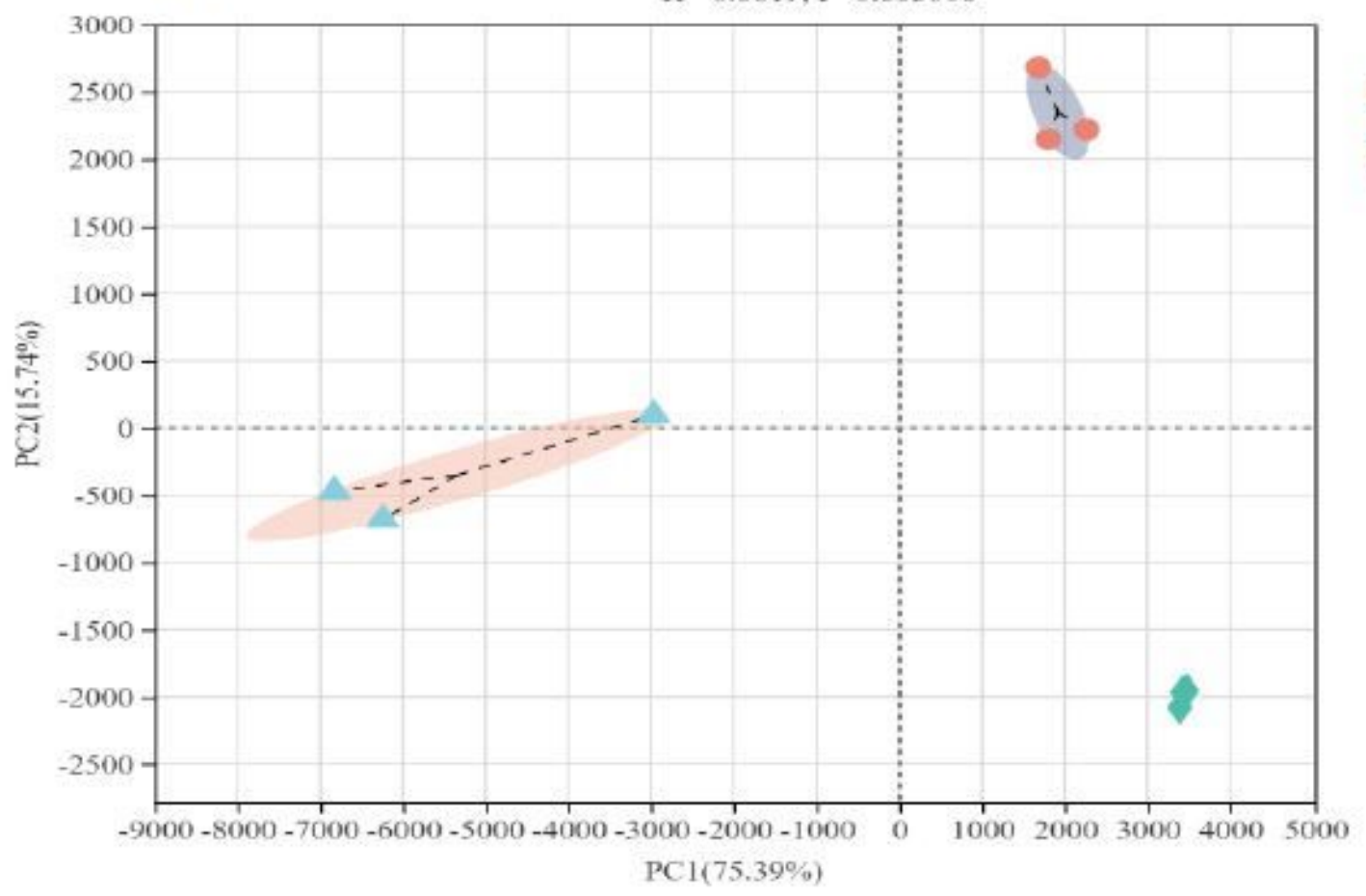

NM

F.m
G.m

(b)

$\mathrm{R}^{2}-0.7940, \mathrm{P}-0.005000$

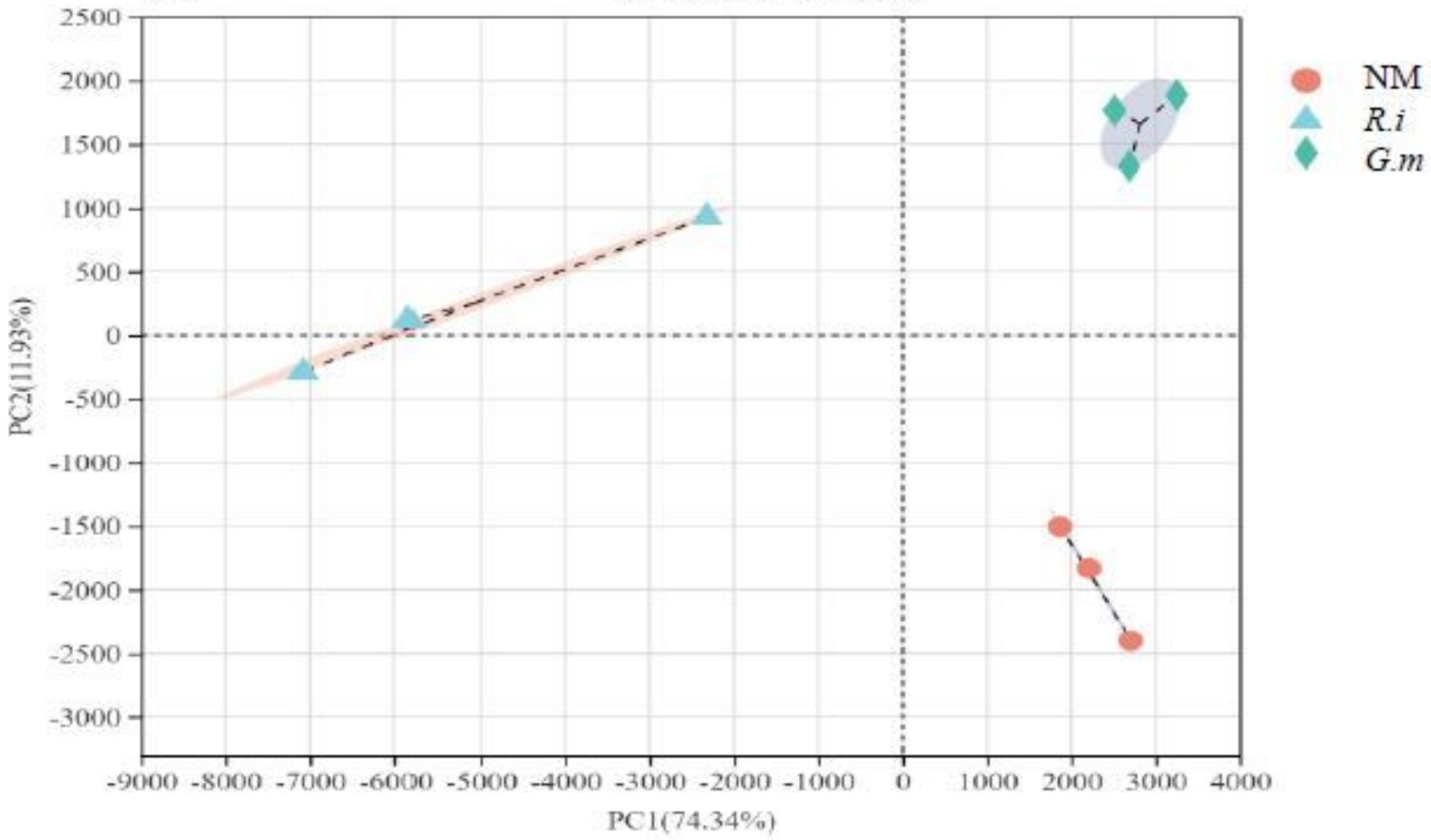

Figure 6

Figure 6 


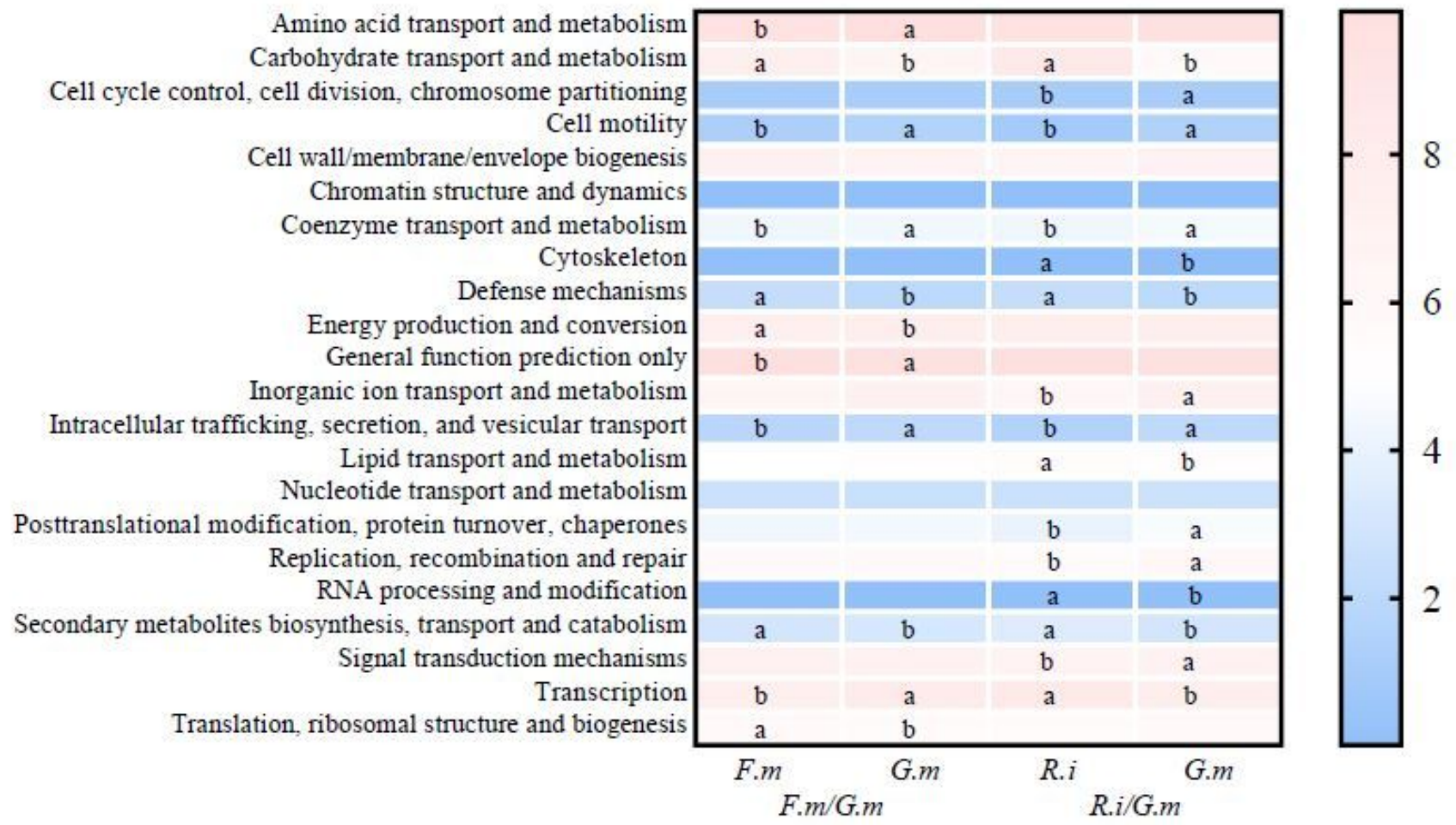

Figure 7

Figure 7

\section{Supplementary Files}

This is a list of supplementary files associated with this preprint. Click to download.

- Supplementaryimformation.docx 